Illinois State University

ISU ReD: Research and eData

Theses and Dissertations

$10-10-2016$

\title{
Effects Of Parasitism And Mite Control Methods On European Starling Development
}

Aderinsola Oluwasikemi Odetunde

Illinois State University, aodetun@ilstu.edu

Follow this and additional works at: https://ir.library.illinoisstate.edu/etd

Part of the Biology Commons

\section{Recommended Citation}

Odetunde, Aderinsola Oluwasikemi, "Effects Of Parasitism And Mite Control Methods On European Starling Development" (2016). Theses and Dissertations. 769.

https://ir.library.illinoisstate.edu/etd/769

This Thesis is brought to you for free and open access by ISU ReD: Research and eData. It has been accepted for inclusion in Theses and Dissertations by an authorized administrator of ISU ReD: Research and eData. For more information, please contact ISUReD@ilstu.edu. 


\title{
EFFECTS OF PARASITISM AND MITE CONTROL METHODS ON EUROPEAN STARLING DEVELOPMENT
}

\author{
Aderinsola Oluwasikemi Odetunde
}

\section{Pages}

Certain developmental stressors can lead to developmental trade-offs in young organisms. Hematophagous ectoparasites are a common stressor experienced by European starlings, and we wished to explore what aspects of an ectoparasite infestation drove trade-offs. The first part of this study was to test the hypothesis that blood loss was the sole mediator of trade-offs due to hematophagous ectoparasite infestation. We used nestlings that were exposed to mites in the nests, nestlings in mite-reduced nests experiencing supplementary blood loss, and nestlings in mite reduced nests with no supplementary blood loss. We also used a new heat treatment to reduce mites in the nest while reducing any side effects on the nestlings. We found that nestlings in mite-enhanced nests did display decreased growth and blood parameters, but nestlings undergoing supplementary blood loss displayed no developmental deficiencies. Nest treatments also did not have a significant effect on nestling immune function. Finally, we found that the heat treatment did reduce mites in the nest prior to hatching, but this effective was lost by the times the nestlings fledged.

Our previous study gave us some insight into the effects of mites on nestling development. However, since the differences in mite abundance were not significant later on in nestling development, some of the results were harder to interpret. In order to properly determine the factors driving trade-offs in the presence of a mite infestation, we had to reassess the different ways we could reduce mite abundance in starling nests. We used this second study to 
analyze different mite control methods on their efficacy and their effects on nestling development. We examined the effects of treating the nests with pesticides, milfoil and heat. We found that while the pesticide treatment was the only one to yield less mites than mite enhanced nests, their nestlings' development in growth, physiological traits and immune function were rarely different than nestlings in mite enhanced nests. Heat treated nests also showed some developmental deficiencies, while not reducing mite abundance.

It appears that blood loss alone does not account for developmental deficiencies associated with mite infestation, but in order to fully understand the effects of these ectoparasites on nestling development, acaricidal treatments with little impact on nestling development must be found and implemented.

KEYWORDS: Developmental trade-off, Ectoparasites, Growth, Immune function, Mite control 


\title{
EFFECTS OF PARASITISM AND MITE CONTROL METHODS ON EUROPEAN STARLING DEVELOPMENT
}

\section{ADERINSOLA OLUWASIKEMI ODETUNDE}

\author{
A Thesis Submitted in Partial \\ Fulfillment of the Requirements \\ for the Degree of \\ MASTER OF SCIENCE \\ School of Biological Sciences \\ ILLINOIS STATE UNIVERSITY
}


Copyright 2017 Aderinsola Oluwasikemi Odetunde 


\title{
EFFECTS OF PARASITISM AND MITE CONTROL METHODS ON EUROPEAN STARLING DEVELOPMENT
}

\author{
ADERINSOLA OLUWASIKEMI ODETUNDE
}

COMMITTEE MEMBERS:

Joseph M. Casto, Chair

Rachel Bowden

Benjamin Sadd 


\section{ACKNOWLEDGMENTS}

I would like to thank my family for their support throughout this process. Many thanks to my advisor Dr. Joseph M. Casto, as well as committee members Drs. Rachel Bowden and Benjamin Sadd for all their advice about my research. Thanks to Drs. Steven Juliano, Scott Sakaluk and E. Keith Bowers for tolerating all of my questions about my statistical analyses. Many thanks to my undergraduate volunteers Michael Dawson, Sarah Balwierczak and Colleen Quinn for their assistance in data collection, both in the field and the lab. Thanks to all my lab mates (past and present): Cody Scholtens, Brenna Knott, Jason Hanser, and Amanda Smith. I also owe thanks to Kelli Brown for helping to keep me sane while working late nights. Finally, I am extremely grateful to the friends I have made while at Illinois State University for all their help and support throughout my time here.

A. O. O. 


\section{CONTENTS}

Page

ACKNOWLEDGMENTS

$\begin{array}{ll}\text { CONTENTS } & \text { ii }\end{array}$

CHAPTER I FIGURES $\quad$ V

CHAPTER II FIGURES Vi vi

CHAPTER I: IS BLOOD LOSS A MEDIATOR OF DEVELOPMENTAL TRADE-OFFS IN

RESPONSE TO HEMATOPHAGOUS ECTOPARASITE INFESTATION? 1

Summary Statement $\quad 2$

$\begin{array}{ll}\text { Abstract } & 2\end{array}$

$\begin{array}{ll}\text { Introduction } & 3\end{array}$

$\begin{array}{ll}\text { Materials and Methods } & 6\end{array}$

Subjects, Study Site, and Ectoparasites $\quad 6$

$\begin{array}{ll}\text { General Field Procedures and Study Design } & 7\end{array}$

Mite Exposure and Infestation Assessment $\quad 8$

Somatic Growth 9

Blood Collection and Processing $\quad 9$

Assessment of Plasma Bacterial Killing Ability $\quad 10$

$\begin{array}{ll}\text { Statistical Analyses } & 11\end{array}$

$\begin{array}{ll}\text { Results } & 13\end{array}$

Egg Spottiness and Mite Abundance 13

$\begin{array}{ll}\text { Brood Reduction } & 14\end{array}$

$\begin{array}{ll}\text { Growth } & 14\end{array}$ 
$\begin{array}{ll}\text { Blood Metrics } & 15\end{array}$

$\begin{array}{ll}\text { Immune Function } & 17\end{array}$

$\begin{array}{ll}\text { Discussion } & 18\end{array}$

$\begin{array}{ll}\text { Mite Manipulation Efficacy } & 19\end{array}$

$\begin{array}{ll}\text { Brood Reduction } & 19\end{array}$

$\begin{array}{ll}\text { Somatic Growth } & 20\end{array}$

$\begin{array}{ll}\text { Blood Metrics } & 22\end{array}$

$\begin{array}{ll}\text { Immune Function } & 23\end{array}$

$\begin{array}{ll}\text { Developmental Trade-offs } & 24\end{array}$

$\begin{array}{ll}\text { References } & 26\end{array}$

$\begin{array}{ll}\text { Figures } & 34\end{array}$

CHAPTER II: THE EFFECTS OF ECTOPARASITE CONTROL METHODS ON MITE ABUNDANCE AND NESTLING PHENOTYPES 44

$\begin{array}{ll}\text { Abstract } & 45\end{array}$

$\begin{array}{ll}\text { Introduction } & 46\end{array}$

$\begin{array}{lr}\text { Materials and Methods } & 49\end{array}$

Subjects, Study Site, and Ectoparasites $\quad 49$

General Field Procedures and Study Design 49

Mite Addition and Mite Burden Assessments $\quad 51$

Assessment of Somatic Growth $\quad 52$

Blood Collection and Processing 52

$\begin{array}{lr}\text { Blood Parameters } & 53\end{array}$

Assessment of Plasma Bactericidal Activity $\quad 54$ 
$\begin{array}{ll}\text { Statistical Analysis } & 54\end{array}$

$\begin{array}{ll}\text { Results } & 56\end{array}$

Hatching Asynchrony $\quad 56$

Brood Reduction $\quad 56$

Experimental Treatments and Measures of NFM Infestation 56

$\begin{array}{ll}\text { Growth } & 57\end{array}$

Hematocrit, Hemoglobin and Blood Glucose Concentrations 57

$\begin{array}{ll}\text { Plasma Bactericidal Activity } & 58\end{array}$

$\begin{array}{ll}\text { Discussion } & 58\end{array}$

$\begin{array}{ll}\text { Mite Control Efficacy } & 59\end{array}$

$\begin{array}{ll}\text { Somatic Growth } & 60\end{array}$

$\begin{array}{ll}\text { Blood } & 61\end{array}$

$\begin{array}{ll}\text { Literature Cited } & 64\end{array}$

$\begin{array}{ll}\text { Figures } & 72\end{array}$ 


\section{CHAPTER I FIGURES}

Figure $\quad$ Page

1. Egg spottiness score across experimental treatments 34

2. Post-fledging mite abundance across experimental treatments 35

3. Effects of experimental treatments on wing length across development 36

4. Effects of experimental treatments on mass across development 37

5. Effects of experimental treatments on tarsus length between treatments 38

6. Effects of age and season on tarsus length 39

7. Effects of experimental treatments on blood glucose concentration across 40 development

8. Effects of experimental treatments on hematocrit across development 41

9. Effects of experimental treatments on hemoglobin across development 42

10. Seasonal effects on RZID 43 


\section{CHAPTER II FIGURES}

Figure $\quad$ Page

$\begin{array}{ll}\text { 1. Mite abundance analyses } & 72\end{array}$

2. Wing length across treatments for BD 5, 10 and 15 nestlings 73

3. Correlation of whole blood and plasma glucose concentrations 74

4. Blood parameter measurements on brood day 15 nestlings across treatment 75 groups 
CHAPTER I: IS BLOOD LOSS A MEDIATOR OF DEVELOPMENTAL TRADE-OFFS IN RESPONSE TO HEMATOPHAGOUS ECTOPARASITE INFESTATION? 


\title{
Summary Statement
}

Relative to nestlings in ectoparasite-reduced nests, and unlike those experiencing ectoparasite enhancement, nestlings experiencing ectoparasite reduction with supplemental blood loss did not differ in their somatic growth, and physiological development.

\begin{abstract}
Stress during ontogeny can force young organisms to alter developmental resource allocation, thus modifying the ensuing phenotype. European starling nestlings shift resources among somatic growth, physiological development, and immune function when reared in nests with substantial hematophagous ectoparasite infestations. These parasites might affect nestlings via blood loss, immune activation, inflammation or other related consequences. We tested whether blood loss in the absence of ectoparasites induces developmental trade-offs that resemble those resulting from ectoparasitism. We assigned starling nests to one of three experimental treatments: mite reduction, mite reduction with nestling blood loss, and mite enhancement, and monitored their somatic growth and survival during post-hatching development. Throughout development, we collected substantial blood samples from nestlings experiencing mite reduction to simulate blood loss due to mite infestation, and smaller samples from nestlings in the other treatments. From these samples, we assessed hematocrit, hemoglobin and blood glucose concentrations, and the bacterial killing ability of plasma. Relative to nestlings that experienced mite removal, nestlings in the mite enhancement treatment had shorter wings, shorter tarsi, and lower levels of hematocrit and hemoglobin. These differences were most prominent in the later stages of development. We also noted a seasonal effect on immune function, where nestlings hatched late in the breeding season had increased bacterial killing ability of plasma relative to
\end{abstract}


nestling that hatched earlier in the season. Taken together, these results suggest that the effects of mite infestation extend beyond those of mere blood loss and its replacement, perhaps due to resource allocation toward immune or inflammatory processes.

\section{Introduction}

The developmental stress hypothesis (Buchanan et al., 2003) posits that early stressors can have profound influences on adult phenotypes, altering physiology, behavior and ultimately fitness in developmentally stressed individuals. Both somatic growth and physiological development require significant resource allocation, and resource demand is especially high in individuals that develop rapidly. Apart from the resource demands of development, animals must also cope with stressors in their environment (Hasselquist and Nilsson, 2012; Maxwell, 1993; Wingfield et al., 1982), which can further tax limited resources driving trade-offs in resource allocation that lead to altered phenotypes (Benard, 2004). Environmental perturbations such as increased predator pressure, inclement weather, temperature extremes, and parasitism can decrease resource availability or increase resource demand, producing a mismatch between required and available resources. Experiencing such a resource bottleneck can force a developing organism to allocate (perhaps adaptively) limited energetic resources to specific aspects of its development, while shunting them away from others. Songbirds are excellent model systems for studying developmental stress, because they exhibit very rapid post-hatching development, which, if perturbed, results in alterations to various aspects of the phenotype (MacDonald et al., 2006; Naguib et al., 2004). Developing songbirds have been used in studies focusing on food deprivation and its effect on sexual signaling, specifically singing ability (Buchanan et al., 2003; Nowicki et al., 1998), however other natural developmental stressors, such as parasitism, and 
associated phenotypic consequences such as altered somatic growth, physiological development or immune function have received comparatively less consideration in relation to developmental stress.

Blood-feeding ectoparasites are ubiquitous environmental stressors in cavity-nesting birds (Johnson and Albrecht, 1993; Mazgajski, 2007; Rendell and Verbeek, 1996), and can dramatically impact nestling development. Studies have shown that ectoparasites can cause decreased growth (Merino and Potti, 1995; Naguib et al., 2006), decreased reproductive success (Naguib et al., 2006), and increased mortality (Badyaev et al., 2006) in birds. In two recent studies of the effects of northern fowl mite (Ornithonyssus sylviarum) infestations on nestling development in European starlings (Sturnus vulgaris), two distinct patterns of somatic growthimmunity trade-offs were reported (Pryor and Casto, 2015; in review). The earlier study assessed the effects of natural variation in mite infestation of nests, and found that relative to nestlings reared in nests with small infestations, those reared with large infestations invested more in innate immunity and less in somatic growth during the phase of rapid post-hatching development (Pryor and Casto, 2015). Conversely, the latter study assessed the effects of experimentally manipulated mite abundance, finding that relative to nestlings from mite-reduced nests, nestlings in mite-enhanced nests actually exhibited decreases in innate immunity while maintaining similar somatic growth during the rapid-growth stage of development (Pryor and Casto, in review). While these equivocal findings likely reflect differences in study design, both studies reported similar effects of variation in mite infestation on nesting hematocrit (packed red blood cell volume) scores. Nestlings from nests with high mite-abundance had significantly lower hematocrit than those from nests with lower mite-abundance (Pryor and Casto, 2015; in review). These findings, while not surprising given that northern fowl mites require blood meals to 
mature and reproduce (Sikes and Chamberlain, 1954), highlight an important developmental character that also may be traded-off with other aspects of development in individuals exposed to stressors.

Blood metrics related to development of the red blood cell compartment and oxygen carrying capacity of blood have been studied developmentally in altricial birds. Hematocrit in starling nestlings increases across development, but may not be a good indicator of physiological condition (Smith and Barber, 2012). Interestingly, hemoglobin concentration appears to be a reliable indicator of many aspects of physiological condition in developing and adult birds (Minias, 2015), and, along with hematocrit, has been proposed as an indicator of the physiological maturation of oxygen carrying capacity (Cuervo et al., 2007; Williams et al., 2012). These blood parameters add significant predictive power to models that use measures of somatic growth to estimate initial post-fledging flight performance of starlings, and tend to lag behind measures of somatic growth in their developmental increase toward adult values (Cornell et al., 2017). While blood loss due to ectoparasite infestation may play a major role in mediating developmental trade-offs that accompany nest infestation, other consequences of infestation could also contribute to these trade-offs.

In addition to causing feeding-induced blood loss, northern fowl mites have been found to vector disease in captive birds (Chamberlain and Sikes, 1955) induce specific antibody production to mite associated antigens (King et al., 2011), and inflammation in response to their bites (Owen et al., 2009), all which likely require some allocation of resources that could influence developmental trade-offs. Mite-induced developmental trade-offs among somatic growth, physiological development and immunity suggest that blood-feeding ectoparasites act as developmental stressors in starlings (Pryor and Casto, 2015; Pryor and Casto; in review); 
however, it remains unclear if these developmental-trade-offs result from blood loss and its associated costs, to some other consequences of infestation, or a combination of these. As all of these traits can be seen as indicators for post-fledging success (Carleton, 2008; Moreno et al., 2005; Morrison et al., 2009), we find it imperative to analyze how certain aspects of mite infestations could influence nestling survival.

Here we test the hypothesis that blood loss and the resources allocated toward its replacement mediate trade-offs among somatic growth, physiological development, and immune function exhibited by nestlings in response to hematophagous ectoparasite infestation. We predicted that, relative to starling nestlings in mite-enhanced nests, nestlings in mite-reduced nests would exhibit faster somatic growth and physiological development, as well as increased immune function, because they would experience fewer competing energetic demands. Additionally, due to the resources needed to replace blood lost to experimental removal, we also predicted that relative to nestlings in mite-reduced nests, nestlings reared in comparable mite-reduced nests but who experienced substantial experimental blood loss would exhibit reduced growth and physiological development, as well as reduced immune function.

\section{Materials and Methods}

\section{Subjects, Study Site, and Ectoparasites}

This research was conducted during the 2015 breeding season on a population of European starlings nesting in nest box colonies in central Illinois. Cedar nest boxes $(n=146$; see Pryor and Casto, 2015, for a detailed nest box description) were located in 4 long-term nest box colony locations in central IL. Adults can raise up to two successful broods annually, and readily nest in nest boxes accessible to researchers (Feare, 1984). All vertebrate animal use in this research was 
in accordance with prevailing local, state, and federal standards and guidelines and approved by the Institutional Animal Use and Care Committee of Illinois State University. All nests that commenced laying in the colonies between the $18^{\text {th }}$ of April and the $23^{\text {rd }}$ of June, and that remained active until the experimental treatments were initiated, were included in the study. At our experimental nest box colonies, the northern fowl mite, when present in nests, is the most abundant blood-feeding ectoparasite found in starling nests at our study sites (Pryor and Casto, 2015), and is a common ectoparasite in starling nests world-wide (Proctor and Owens, 2000). Mites were collected from the previous summer's old nest material, and were kept in the lab for later mite addition to nests (see below).

\section{General Field Procedures and Study Design}

During the 2015 breeding season, nests were checked every three days for clutch initiation, at which point they were checked daily until clutch completion. Each nest was then alternately assigned to one of the three experimental treatment groups: mite reduction (MR), mite reduction and blood loss (MRBL) and mite enhancement (ME). Once clutch completion was confirmed, all nests were microwaved to reduce mite abundance. MR and MRBL nests were placed back in their boxes after microwaving, while ME nests had mites added before they were placed back in the nest box (vide infra). Beginning 10 days after clutch completion, nests were checked daily to monitor egg hatching. Once hatched, each nestling had a single toenail clipped to provide a unique within nest identifier. The day on which a majority of eggs had hatched was designated as brood day (BD) 0 . On $\mathrm{BD} 0$ and $\mathrm{BD} 10$, all nests underwent their respective experimental treatments. Nestlings and unhatched eggs were removed from the nest and placed in an insulated container until experimental treatments were completed, at which time, they were returned to the 
nest. MRBL and MR nests were removed from the nest box, microwaved for 30 seconds, then returned to the nest box. Prior to returning nest to boxes, nest box interiors were swept with a stiff brush and flamed with a butane torch to remove debris and lingering ectoparasites. On the brood days that MR and MRBL nests were treated, ME nests were removed from the box and then returned to simulate similar disturbance.

\section{Mite Exposure and Infestation Assessment}

Northern fowl mites (NFM) used in the ME treatment were obtained from old nest material collected prior to the start of the breeding season. Approximately 40 NFM (predominantly unfed protonymphs) were transferred from the old nesting material to the new nest after it was microwaved following clutch completion. Ten days after clutch completion, the eggs in all nests were visually checked for spots on eggs caused by the mites taking blood meals from incubating adults. Egg spottiness was ranked on a scale from 0-3 using modified methods of Pryor and Casto (in review). A score of zero indicated an average of less than 1 blood spot/egg, a score of one indicated an average of $1-10$ blood spots/egg, a score of two indicated $11-50$ blood spots per egg, and a score of three indicated an average of greater than 50 blood spots/egg. In addition to noting egg spottiness prior to hatching, on the day after all nestlings had fledged from a nest, a sample of mites was systematically collected from the nest for counting. Northern fowl mites are attracted to warmth and increase locomotion in response to vibration (Owen et al., 2005), so to collect a sample of them, a warm, reusable water-filled, plastic ice cube was placed in the nest for one minute, allowing mites to discover and then crawl over it. After one minute, the ice cube was retrieved with forceps and placed in jar containing $70 \%$ ethanol to kill and preserve the 
mites. The solution was later filtered and the filter contents transferred to a grid-lined petri dish for counting under a dissecting microscope.

\section{Somatic Growth}

On BD 5, 10 and 15, the mass, tarsus length and wing length of each nestling was measured using an electronic balance, digital calipers, and a metric wing ruler, respectively. Additionally, on brood day 10 all nestlings received U.S. Fish and Wildlife Service aluminum leg bands.

\section{Blood Collection and Processing}

Blood samples were collected via brachial venipuncture with a 26-gauge needle, into heparinized capillary tubes, and stored on ice until processed. Nestlings in the MR and ME treatments had $50 \mu \mathrm{L}$ of blood collected on BD 5 and BD 10 for determination of hematocrit, hemoglobin concentration, blood glucose concentration, and bacterial killing ability. Nestlings in the MBR treatment had $300 \mu \mathrm{L}$ of blood collected on BD 5 and $650 \mu \mathrm{L}$ collected on BD 10, which is $\approx 1 \%$ of body weight (Feare, 1984 ) and $\approx 10 \%$ of the total blood volume (Owen, 2011) in an average nestling at those ages. The extra blood removal from MRBL nestlings was intended to simulate the magnitude of blood loss a nestling might experience while under mite infestation. Nestlings in all experimental treatment groups had $250 \mu \mathrm{L}$ of blood collected on BD 15 , as no measurements were collected from nestlings thereafter. Stopwatches were used to record time of initial nest disturbance, time of each nestling's removal from nest, and time taken to bleed each nestling. Capillary tubes were centrifuged at $13,300 \mathrm{rpm}(17,000 \mathrm{~g})$ for $10 \mathrm{~min}$ in a micro-hematocrit centrifuge, and hematocrit was measured with a micro-capillary reader (model 
220, Damon/IEC; Needham Heights, MA). Plasma was harvested and was stored frozen at $-80^{\circ}$

$\mathrm{C}$ in microcentrifuge tubes until used to assess bacterial killing ability.

Blood glucose concentration was assessed in the field using $\approx 2 \mu 1$ of whole blood and a commercially available blood glucose reader and test strips (ReliOn micron, Arkray USA, Edina, $\mathrm{MN})$. To assess hemoglobin concentration, $5 \mu \mathrm{l}$ of blood was preserved in $1.25 \mathrm{ml}$ of Drabkin's solution (Sigma-Aldrich; St. Louis, MO) while in the field. The whole blood preserved in Drabkin's solution was used for quantification of hemoglobin concentration using the cyanmethemoglobin method (Drabkin and Austin, 1932), with absorbance measured at $540 \mathrm{~nm}$ on a microplate spectrophotometer (BioTek, Epoch; Bio-Tek Instruments, Winooski, VT, USA).

\section{Assessment of Plasma Bacterial Killing Ability}

The bacterial killing ability of plasma was quantified using a zone of inhibition assay modified from a protocol by Moret and Schmid-Hempel (2000). DH5 $\alpha$ Escherichia coli was cultured at $37{ }^{\circ} \mathrm{C}$ in $6 \mathrm{~mL}$ of sterile broth medium $(5 \mathrm{~g}$ bacto-tryptone, $2.5 \mathrm{~g}$ yeast extract, $5 \mathrm{~g}$ $\mathrm{NaCl}$ in $500 \mathrm{~mL}$ of distilled water, $\mathrm{pH} 7.5$ ) with $0.7 \%$ agar at $50{ }^{0} \mathrm{C} .300 \mu \mathrm{L}$ of chicken egg white in 1.0 M PBS $\left(100 \mathrm{~g} \mathrm{~L}^{-1}\right)$ was also added to aid in the lysis of E. coli. Ten wells were made in each plate with a Pasteur pipette, and $2 \mu \mathrm{L}$ of thawed and vortex-mixed, pure plasma samples were placed in eight of the wells. The remaining two wells contained a positive control ( $25 \mu \mathrm{g}$ $\mathrm{mL}^{-1}$ gentamicin) and a negative control (LB broth). Plates were placed upside down and incubated at $40^{\circ} \mathrm{C}$ for 24 hours. Perti dishes were then photographed using a magnifying HD digital video camera (Videoflex 7200HD; ken-a-vison, Kansas City, MO, USA) and the diameter of the zones of inhibition for each sample and the positive control were measured twice (horizontally and vertically) using digital image analysis software (Applied Vision 4; ken-a- 
vison, Kansas City, MO, USA). To quantify the immune response of individual nestlings, the average diameter of the zones of inhibition for each duplicate sample was divided by the average diameter of the positive control on the same dish, giving a relative zone of inhibition. Relative zone of inhibition diameters (RZID) of duplicates were then averaged.

\section{Statistical Analyses}

Our main goal was to determine whether blood loss, a consequence of NFM infestation in starlings, influenced trade-offs among traits that are indicative of post-fledging success. Nests where no young survived to leave the nests would not provide insight into the sustained effects of these stressors. For this reason, we chose to only include nests in which at least 1 nestling survived to fledging for statistical analyses. To account for seasonal variation in our data, all nests in the study with eggs that hatched were categorized into early-season and late-season broods. In order to differentiate early- and late-season broods, we determined the earliest likelihood of first-brood fledgling independence from parents, and then estimated the earliest date that a subsequent second clutch of eggs laid by the same mother would likely begin hatching (12-June). All broods that began hatching prior to that date were considered early-season broods, and those that commenced hatching after that date were deemed late-season broods. Early-season broods likely consisted of offspring of first clutches as well as young from intermediate clutches that were replacements for nesting attempts that failed relatively early in the nesting sequence (Feare, 1984). Late-season broods were likely the result of maternal re-nesting attempts following successful fledging of young from first clutches, or unsuccessful first, or later, clutches. 
Egg spottiness scores were analyzed with a one-tailed planned contrast between the ME treatment and both mite reduction treatments (MR and MRBL; a.k.a. heat-treated nests). The blood loss component of the MRBL group did not occur until after egg spottiness was assessed, thus both experimental treatments were identical at that stage of the study, and these heat-treated nests were expected to have fewer mites and associated indicators than nests in the ME treatment. Post-fledging mite abundance (hereafter "mite abundance") resulting from experimental treatment was analyzed using a one-way ANCOVA, with BD 0 date as the covariate. To assess the relationship between infestation metrics, we also regressed mite abundance onto egg spottiness score.

To determine if the treatments had any effect on brood reduction, the proportion of nestlings that died prior to fledging in each successful nest was calculated, and then compared among treatments using a two-way ANOVA, with experimental treatment and season as betweensubject's factors.

Each dependent measure of somatic growth (mass, tarsus length, wing length), physiological development (hematocrit and hemoglobin concentration), immune function (bacterial killing ability), as well as blood glucose concentrations were averaged across nestlings within nests. These dependent variables were analyzed using mixed-model analyses of variance (ANOVA) with one within-subjects factor (nestling age) and two between-subjects' factors (experimental treatment, and season). Where appropriate, we used least square mean differences for post-hoc comparison of statistically significant main effects and interactions. An estimate of hatch date for each nest (BD 0) was converted to a Julian date to be used as a covariate in an ANCOVA to replace season when the assumptions of an ANOVA were violated. 
Least square means were used for visualizing all analyses, and the following response variables used transformed data to satisfy all assumptions of normality in the statistical tests: mite abundance (log transformation), brood reduction (arcsin-transformation), tarsus (cube transformation), blood glucose (reciprocal transformation). For variables that required data transformation, back-transformed means and standard errors were calculated and used for graphical display. If a nest was missing data for a variable, it was only omitted from analyses requiring those data. All statistical analyses were performed using SAS 9.4 software (SAS Institute Inc.; Cary, NC).

\section{Results}

In total, 75 nests were initially microwaved and assigned to an experimental treatment (27 MR, $25 \mathrm{MRBL}$, and $23 \mathrm{ME}$ ), and of these nests, 62 produced hatchlings (23 MR, $19 \mathrm{MRBL}$, and $20 \mathrm{ME})$. After eliminating nests that fledged no young, as well as 4 nests (1 MR, $1 \mathrm{MRBL}$, and $2 \mathrm{ME}$ ) due to technical complications, we were left with 43 nests (18 MR, $11 \mathrm{MRBL}$, and 14 $\mathrm{ME})$.

\section{Egg Spottiness and Mite Abundance}

A one-tailed contrast showed that the ME treatment yielded a significantly higher mean egg spottiness score than the heat treatments $(\mathrm{p}=0.0296$; Figure 1). Mite abundance was not significantly affected by experimental treatment ( $p>0.1$; Figure 2$)$, but there was a significant effect of the covariate (i.e., BD 0 date) on mite abundance $(\mathrm{p}=0.0009)$, indicating that mite abundance increased as the breeding season progressed. Results of the linear regression showed 
there was no significant correlation between the egg spottiness score of nests and their mite abundance $\left(r^{2}=0.002, p=0.7848\right)$.

\section{Brood Reduction}

We found no differences in the likelihood of brood reduction among the treatment groups $\left(\mathrm{F}_{(2,37)}=1.60, \mathrm{p}=0.2154\right)$. While non-significant, there was a trend of late-season broods experiencing less brood reduction than early-season broods $\left(\mathrm{F}_{(1,37)}=3.61, \mathrm{p}=0.0653\right)$.

\section{Growth}

As expected, wing length increased significantly with nestling age $\left(\mathrm{F}_{(2,70)}=15821.5, \mathrm{p}<\right.$ $0.0001)$, but it also varied significantly among experimental treatments $\left(\mathrm{F}_{(2,35)}=4.5, \mathrm{p}=0.0182\right.$;

Figure 3), with MR and MRBL nestlings exhibiting longer wings than ME nestlings $(\mathrm{p}<0.02$ for both). Wing length was also significantly greater in early-season than in late-season broods $\left(F_{(1,35)}=11.60, p=0.0017\right)$. A significant interaction between nestling age and experimental treatment $\left(\mathrm{F}_{(4,70)}=3.69, \mathrm{p}=0.0088\right)$ revealed that while there were no differences in mean wing length of broods among experimental treatments on BD $5(\mathrm{p}>0.05)$, and no differences between brood means of MR and MRBL nests on BD 10 and BD $15(\mathrm{p}>0.05)$, broods in both of those experimental treatments exhibited significantly longer wing lengths than ME broods at those ages $(\mathrm{p}<0.03)$. Additionally, a significant interaction between nestling age and season $\left(\mathrm{F}_{(2,70)}=\right.$ 4.74, $\mathrm{p}<0.0017)$ showed that while at all ages early-season broods had longer wing lengths than late-season broods $(\mathrm{p}<0.05)$, the differences of least squares means between early- and lateseason broods tended to be smaller on BD 5 (2.26) than on BD 10 and 15 (4.28 and 4.03, respectively). 
Mass also significantly increased with nestling age $\left(\mathrm{F}_{(2,74)}=2765.86, \mathrm{p}<0.0001\right)$ and varied significantly with experimental treatment $\left(\mathrm{F}_{(2,37)}=4.12, \mathrm{p}=0.0242\right)$, with $\mathrm{MR}$ and $\mathrm{MRBL}$ nestlings weighing more than ME nestlings. Late-season nestlings weighed less than earlyseason nestlings $\left(\mathrm{F}_{(1,37)}=14.52, \mathrm{p}=0.0005\right)$. A significant interaction between experimental treatment and nestling age $\left(\mathrm{F}_{(4,74)}=2.93, \mathrm{p}=0.0265\right)$ showed that MR nestlings were heavier than ME nestlings on BD 5 and BD $10(p<0.01)$, but not on BD $15(p>0.05)$. There was no difference shown between MRBL and ME nestlings on BD 5 ( $p>0.05)$, but MRBL nestlings weighed more on BD 10 and BD $15(\mathrm{p}<0.01)$. A significant three-way interaction between experimental treatment, nestling age and season $\left(\mathrm{F}_{(4,74)}=9.21, \mathrm{p}<0.0001\right.$; Figure 4), indicated that in early-season broods, MR nestlings, but not MRBL nestlings, were heavier than ME on BD 10 and BD $15(\mathrm{p}<0.05)$, while in late-season broods, MRBL nestlings, but not MR nestlings, were significantly heavier than ME nestlings on BD 10 and BD $15(\mathrm{p}<0.05)$.

Tarsus length varied significantly across experimental treatments $\left(\mathrm{F}_{(2,37)}=3.91, \mathrm{p}=0.0288\right.$; Figure 5), with MRBL and MR nestlings having longer tarsi than the ME nestlings $(\mathrm{p}<0.05)$. Tarsus length also increased significantly with nestling age $\left(\mathrm{F}_{(2,74)}=2069.87, \mathrm{p}<0.0001\right.$; Figure $6)$, and was significantly greater in early-season broods than late-season broods $\left(\mathrm{F}_{(1,37)}=10.82, \mathrm{p}\right.$ $=0.0022)$.

\section{Blood Metrics}

Blood glucose varied significantly with nestling age $\left(\mathrm{F}_{(2,74)}=3.42, \mathrm{p}=0.0381\right)$, and there was also a significant interaction between treatment, nestling age and season $\left(\mathrm{F}_{(4,74)}=4.58, \mathrm{p}=\right.$ 0.0023). Despite undergoing similar treatments until BD 5, MR nestlings displayed higher blood glucose concentrations than MRBL nestlings on BD 5 in early-season broods $(\mathrm{p}<0.01$; Figure 
7). Similarly, MR nestlings displayed higher blood glucose concentrations than MRBL nestlings on BD 15 in late-season broods ( $\mathrm{p}<0.03$; Figure 7). ME nestlings had higher blood glucose concentrations than MR nestlings on BD 15 in early-season broods $(\mathrm{p}<0.03)$, and BD 5 in lateseason broods $(\mathrm{p}<0.04)$. MRBL nestlings exhibited lower blood glucose than ME nestlings on BD 15 in both the early and late season ( $\mathrm{p}<0.04$ for both seasons).

Experimental treatment affected hematocrit significantly $\left(\mathrm{F}_{(2,36)}=9.23, \mathrm{p}=0.0006\right)$, with MRBL nestlings displaying more hematocrit than MR nestlings $(\mathrm{p}<0.02)$, and ME nestlings having less hematocrit than MR nestlings $(\mathrm{p}<0.05)$. Hematocrit was also greater in early-season broods than late season broods $\left(\mathrm{F}_{(1,36)}=18.72, \mathrm{p}=0.0001\right)$, and increased with nestling age $\left(\mathrm{F}_{(2,72)}=27.30, \mathrm{p}<0.0001\right)$. A significant interaction between experimental treatment and nestling age showed that while hematocrit of ME nestlings showed no change across development $(\mathrm{p}>0.05)$, in MR and MRBL nestlings, hematocrit increased with nestling age $(\mathrm{p}<$ 0.0001 for both). The significant interaction between nestling age and season revealed that hematocrit on BD 5 was similar in the early- and late-season broods $(\mathrm{p}>0.05)$, yet early-season broods had higher hematocrit on BD 10 and BD 15 ( $p<0.05$ and $\mathrm{p}<0.0001$, respectively). A significant three-way interaction with nestling age, season and experimental treatment $\left(\mathrm{F}_{(4,72)}=\right.$ $3.63, \mathrm{p}=0.0094)$, indicated that in early-season broods, ME nestlings had lower hematocrit volumes than MRBL and MR nestlings on BD 15 ( $\mathrm{p}<0.0001$ for both; Figure 8), and in lateseason broods ME nestlings also had lower hematocrit than MRBL nestlings on BD 15 (p < $0.002)$.

Nestling hemoglobin was significantly affected by experimental treatment $\left(\mathrm{F}_{(2,37)}=13.86, \mathrm{p}<\right.$ 0.0001; Figure 9), with MRBL nestlings exhibiting higher concentrations than MR nestlings ( $<<$ 0.03), who likewise exhibited higher hemoglobin concentrations than ME nestlings $(\mathrm{p}<0.002)$. 
Hemoglobin concentration increased with nestling age $\left(\mathrm{F}_{(2,74)}=56.35, \mathrm{p}=0.0001\right)$ and decreased across the breeding season $\left(\mathrm{F}_{(1,37)}=5.93, \mathrm{p}=0.0198\right)$. A significant interaction between treatment and age $\left(\mathrm{F}_{(4,74)}=4.16, \mathrm{p}=0.0043\right)$ showed that MR and MRBL nestlings had more hemoglobin than ME on BD 5 ( $p<0.03$ and $\mathrm{p}<0.001$, respectively) and BD 15 ( $p<$ 0.0001 for both), but only MRBL nestlings had more hemoglobin than ME nestlings on BD 10 (p $<0.03)$. Nestling age and season also exhibited a significant interaction $\left(\mathrm{F}_{(2,74)}=7.13, \mathrm{p}=\right.$ 0.0015); nestlings in the early-season broods had higher hemoglobin concentrations than their late-season counterparts on BD 10 and BD 15 ( $p<0.02$ and $p=0.0005$, respectively), but not BD $5(\mathrm{p}>0.05)$. A significant three-way interaction between experimental treatment, nestling age and season showed that in the early-season, MRBL and MR nestlings had similar hemoglobin concentrations to ME nestlings on BD 5 and BD 10 ( $p>0.05$ for both), but were significantly higher on BD 15 ( $p>0.0001$ for both). In the late-season, MR nestlings had greater hemoglobin concentrations than ME nestlings on BD 5 ( $\mathrm{p}<0.02)$, but not on BDs 10 and BD 15 $(p>0.05)$. MRBL nestlings had higher hemoglobin concentrations than ME nestlings on BD 5 and BD $15(\mathrm{p}<0.002$ and $\mathrm{p}<0.005$, respectively), but not BD $10(\mathrm{p}>0.05)$.

\section{Immune Function}

Experimental treatment did not significantly affect bacterial killing ability of nestling plasma $\left(\mathrm{F}_{(2,36)}=0.47, \mathrm{p}=0.6287\right)$. However, bacterial killing ability of plasma increased with nestling age $\left(\mathrm{F}_{(2,72)}=51.45, \mathrm{p}<0.0001\right)$, and there was a significant effect of season, with late-season broods displaying increased immune function relative to early-season broods $\left(\mathrm{F}_{(1,36)}=5.38, \mathrm{p}=\right.$ 0.0262; Figure 10). There was also an effect of nestling age $\left(\mathrm{F}_{(2,72)}=51.45, \mathrm{p}<0.0001\right)$, with immune function increasing from BD 5 to $10(\mathrm{p}<0.0001)$ but not from BD 10 to $15(\mathrm{p}>0.05)$. 


\section{Discussion}

Our goal was to determine the role of blood loss and replacement in mediating ectoparasiteinduced developmental trade-offs. We hypothesized that replacement of blood lost to bloodfeeding ectoparasite infestation utilizes limited developmental resources, thus affecting other resource-dependent developmental processes such as somatic growth, physiological development and immune function. We anticipated that heat treatment of MR and MRBL nests throughout nestling development would significantly reduce mite abundance relative to ME nests, and predicted that relative to ME nestlings, MR and MRBL nestlings would exhibit enhanced somatic growth and physiological development, as well as altered immune function. Due to the resources needed to replace blood lost to experimental removal, we also predicted that relative to MR nestlings, MRBL nestlings would exhibit slower somatic growth and physiological development, and altered immune function. Heat-treated nests did exhibit a transient reduction in ectoparasite burden, albeit not as large or as persistent as we had anticipated. As predicted, MR and MRBL nestlings grew more rapidly and had higher hematocrit and hemoglobin concentrations than ME nestlings, but exhibited comparable innate immunity. Contrary to our second prediction, MR nestlings did not grow more rapidly than MRBL nestlings, and surprisingly exhibited lower hematocrit and hemoglobin concentrations than MRBL nestlings. Taken together, these findings suggest that previously reported developmental trade-offs associated with blood-feeding ectoparasite infestations cannot be accounted for solely by the costs associated with mere blood loss, as developmental blood loss in mite reduced nestlings appears to hasten, not slow, physiological development. 


\section{Mite Manipulation Efficacy}

Based on the significant influence of nest treatments on egg spottiness scores, heat treatments reduced ectoparasite infestation during incubation. However, later mite abundance following nest leaving was unaffected by the experimental nest treatments, suggesting that the effectiveness of microwaving nests to reduce infestation waned despite repeated bouts of re-microwaving across nestling development. Heat treatment of pied flycatcher nests, similar to that used here, produces substantial reductions in blowfly, mite, and flea infestations (López-Arrabé et al., 2014). The size of the starling nest boxes used at our field sites (Pryor and Casto, 2015) are substantially larger than those typically used in studies of pied flycatchers (Lambrechts et al., 2010) and perhaps the temporary reduction in infestation seen in our starling nests with heat treatment may be in part due to incomplete heating of the entire nest due to unavoidable cold spots in nests that nearly fill the microwave oven chamber. All nestling data was collected between the two time points when infestation metrics were assessed, and despite the apparent transient treatment differences in ectoparasite infestations across nestling development, significant differences in nestling response variables between the MR and ME treatments, suggest that even transient differences in ectoparasitism during development substantially influence nestling phenotypes.

\section{Brood Reduction}

Despite significant treatment effects on growth and physiological development, brood reduction did not differ across treatments, suggesting that the treatment effects were not so great as to induce treatment-associated mortality. This suggests that the treatments did not differentially affect the most vulnerable nestlings in broods. This finding is important, as loss of the most vulnerable nestlings between brood days 5 and 15 from only certain treatments could 
alter reported patterns of nestling development (e.g., treatment-associated compensatory growth) which were based on brood averages.

\section{Somatic Growth}

Mite enhancement lead to decreased growth relative to the MRBL and MR treatments, supporting our prediction that starling nestlings shift resource allocation away from physical growth in response to mite infestations. These results support other work examining the effect of ectoparasites on nestling growth (Fitze et al., 2004; Merino and Potti, 1995; Saino et al., 1998). These treatment differences in somatic growth were most apparent on BD 10 and 15, indicating that the effects of mite infestation may be cumulative to the nestlings. There is also the possibility that these differences were so apparent late in development due to the timing of the treatments. ME nestlings were exposed to NFM as soon as they hatched, but the MRBL did not experience supplementary blood loss until 5 days post-hatch. Removing blood from the MRBL nestlings prior to BD 5 would ensure that nestlings would experience blood loss more comparable to the ME treated nestlings. While BD 5 is the earliest we have tried to take blood from starling nestlings, collecting at an earlier age may be possible, given the larger size of these nestlings, relative to other birds. This could be done by either removing smaller volumes of blood from hatching until BD 5. An alternative approach to blood loss could be the injection of phenylhydrazine hydrochloride (PHZ), a drug which can induce reductions in hematocrit and hemoglobin in starlings for up to 10 days (Williams et al., 2012). While this method does not directly emulate blood removal seen in mite infestations, it does mimic some of the effects of a mite infestation (decreased hematocrit and hemoglobin), while reducing the number of nest disturbances relative to bleeding the birds daily. 
The effects of the ME treatment were small, with those nestlings showing 3-5\% reductions in various growth measures, relative to the MR treatments. The significant differences in growth may not fully demonstrate the severity of NFM infestation on nestling development, as there may have some adjustment behavior due to infestation, from both adults and nestlings. Blue tit nestlings have been shown to increase begging behavior when living in ectoparasite-infested nests (Christe et al., 1996), and parents tend to increase their feeding rates when facing ectoparasite infestation, leading to no reductions in growth compared to nestlings that grew in parasite-free nests (Bouslama et al., 2002; Tripet and Richner, 1997). Therefore, it could be possible that starling adults increase nestling provisioning in heavily infested nests.

MRBL and MR nests showed no differences in measures of somatic growth, contrary to our prediction that the MRBL treatment would lead to reduced growth and physiological development relative to the MR treatment. This could be evidence to support our hypothesis that the developmental deficiencies from mite infestations were due to not only blood loss, but also supplementary mite factors. We presumed that $10 \%$ of blood volume at a time would adequately mimic the blood lost by a nestling during an infestation, but it may be insufficient relative to how much blood the mites are taking. In addition, the large amounts of blood removed on two separate occasions is a slightly different pattern of blood removal than what mite-infested nestlings would experience. Removing smaller amounts of blood from when the nestlings hatched to BD 15 may have been more true-to-life, but would have required more nest disturbances by the experimenters, and it has been shown that human disturbances can raise corticosterone levels and rates of nest abandonment (Strasser and Heath, 2013). 


\section{Blood Metrics}

The ME treatment did not yield increased glucose relative to the MR and MRBL treatments, nor was there any effects of season on this measurement, as we had initially predicted. Elevated glucose in high mite-abundance nests was observed in a previous experiment (Pryor and Casto, 2015), and was assumed to be part of the stress response to compensate for resources lost to the parasites, or a consequence of the parents increasing feeding in response to the ectoparasites in the nest. While the lack of difference in blood glucose may be an indication that the ME treatment did not elicit a stress response in the nestlings, it could also be due to the heat-treated and mite infested nests having similar mite abundances. We expected to see the time in the breeding season and glucose concentration to have a positive relationship, as starlings may have responded to this stressor by increasing food provisioning to replace the energy lost. Starlings at our field sites have been shown to feed nestlings mulberries from nearby trees that grow fruit in the late season, so we expected starlings to feed more of them to their young to mitigate deficiencies due to ectoparasite abundance. However, since most of the traits measured decreased in the late-season broods, it may be that the amount of available resources were generally lacking, so feeding nestlings more high sucrose foods may have not been enough to significantly elevate ME blood glucose relative to the other treatment groups.

The deficiencies in hematocrit and hemoglobin in ME treated nestlings could be an indicator of reduced body condition. Hematocrit volume and hemoglobin concentration both are both major factors in how efficiently oxygen can be transported in the body (Calbet et al., 2006). It has been suggested that hemoglobin and hematocrit may be major factors in a fledging's ability to perform sustained flight (Cornell et al., 2017), which would be very beneficial in avoiding predation. This may mean that nestlings exposed to heavy mite infestations may show impaired 
flight ability, which could negatively affect their fitness. Like the growth parameters, these differences of ME hematocrit and hemoglobin relative to MR were most prominent at BD 15, but they were more extreme (17\% and $31 \%$ in the early brood, respectively). This stark difference suggests that more resources were shunted away from these traits than with growth, and having impaired hematocrit and hemoglobin development prior to fledging can cause these nestlings to display poorer flight ability than nestlings in mite-treated nests, and thus would be more susceptible to predation.

While the mite-enhanced nestlings had reduced hemoglobin and hematocrit later in development, the difference between ME and MRBL nestlings was steeper for hemoglobin than hematocrit. This may have been due to reticulocytes, immature red blood cells that contain about $20 \%$ of the hemoglobin found in mature red blood cells (Minias, 2015). Generation of these cells can increase hematocrit volume, but have little effect on hemoglobin concentration, making hemoglobin a more accurate gauge of nestling oxygen carrying capacity.

\section{Immune Function}

While the difference in mite abundance between experimental treatments was not significant, the seasonal effects of mite abundance give us better insight in how mite infestations can alter immune function. Certain ectoparasites have been shown to activate immune function (Biard et al., 2015; Saino et al., 1998), and considering nestlings that hatched later in the season experienced higher mite abundance and increased immune function, that seems to be the same with NFM. This mirrors work completed on Darwin's finches, where finch populations on islands with higher ectoparasite density invested more in immune function than finches in lower parasite density populations (Lindström et al., 2004). The reason these effects were not visible 
when comparing nest treatments may have been the transient effects of the heat treatment, as post-fledging mite loads were similar across treatment groups. Whether this effect of NFM on immune function is due to the contents of the mite's saliva, possible transference of bacteria, or the bite itself that causes this action, this shows us that blood loss is not the primary mechanism by which mites act as a developmental stressor to nestlings.

\section{Developmental Trade-offs}

There did not appear to be any change in resource investment towards nestling immune function between different treatment groups. However, nestlings hatched later in the field season did show a decrease in growth, but an increase in immune function relative to their early brood counterparts. This may be due to the difference in mite loads being more distinct between early and late season broods than across treatments.

However, these results are harder to interpret due to the results of the post-fledging mite abundance in the nests. The microwave method did not seem to be effective at reducing mite abundance, so there was no significant difference in post-fledging mite abundance across the experimental treatment groups. Thus, it is hard to determine the true effects of blood loss on the nestlings of those experimental treatments, as the number of mites may have contributed some negative effects to the nestlings' development. In order to have a better understanding of the different aspects of mite infestation on nestling development, a more effective method of mite removal must be implemented.

In conclusion, we found that ME nestlings exhibited decreased growth, as well as decreased hematocrit and hemoglobin relative to control nestlings. MRBL nestlings did not exhibit any developmental deficiencies, possibly verifying that blood loss alone does not account for all the 
developmental deficiencies observed in nestlings suffering from ectoparasites. Nestling immune function did not yield any significant differences across experimental treatments, but late season nestlings did have increased immune function, as well as increased mite abundance. Further adjustments on the method of mite control used may allow for more distinct mite levels between experimental treatment groups, and reduce any confounding effects on mite abundance on the parameters measured throughout the experiment.

\section{Acknowledgements}

Thanks to the lab mates and volunteers who assisted me in the field, as well as in the lab, generating data. Thanks to Dr. Steve Juliano and Dr. Keith Bowers for statistical assistance. Thanks to Dr. Ben Sadd for supplying the DH5a E. coli for the immunoassays.

\section{Competing Interests}

No competing interests declared.

\section{Funding}

Funding was provided by the Phi Sigma Biological Honors Society, Beta Lambda Chapter and the Illinois Ornithological Society to AOO, and from the Health Resources and Services Administration, Department of Health and Human Services (DHP 20062), and the Center for Math, Science and Technology at Illinois State University to JMC. 


\section{References}

Badyaev, A. V, Hamstra, T. L., Oh, K. P. and Acevedo Seaman, D. A. (2006). Sex-biased maternal effects reduce ectoparasite-induced mortality in a passerine bird. Proc. Natl. Acad. Sci. U. S. A. 103, 14406-11.

Benard, M. F. (2004). Predator-induced phenotypic plasticty in organisms with complex life histories. Annu. Rev. Ecol. Syst. 35, 651-673.

Biard, C., Monceau, K., Motreuil, S. and Moreau, J. (2015). Interpreting immunological indices: The importance of taking parasite community into account. An example in blackbirds Turdus merula. Methods Ecol. Evol. 6, 960-972.

Boonstra, R. (2004). Coping with changing northern environments: the role of the stress axis in birds and mammals. Integr. Comp. Biol. 44, 95-108.

Bouslama, Z., Lambrechts, M. M., Ziane, N., Djenidi, R. D. and Chabi, Y. (2002). The effect of nest ectoparasites on parental provisioning in a north-African population of the Blue Tit Parus caeruleus. Ibis (Lond. 1859). 144, E73-E78.

Brown, C. R., Bomberger Brown, M. and Rannala, B. (1995). Ectoparasites reduce long-term survival of their avian host. Proc. R. Soc. B Biol. Sci. 262, 313-319.

Buchanan, K., Spencer, K., Goldsmith, A. and Catchpole, C. (2003). Song as an honest signal of past developmental stress in the European starling (Sturnus vulgaris). Proc. R. Soc. London B Biol. Sci. 270, 1149-1156.

Calbet, J. A. L., Lundby, C., Koskolou, M. and Boushel, R. (2006). Importance of hemoglobin concentration to exercise: Acute manipulations. Respir. Physiol. Neurobiol. 151, 132-140. 
Carleton, R. E. (2008). Ectoparasites affect hemoglobin and percentages of immature erythrocytes but not hematocrit in nestling Eastern Bluebirds. Wilson J. Ornithol. 120, 565568.

Chamberlain, R. W. and Sikes, R. K. (1955). Laboratory investigations on the role of bird mites in the transmission of eastern and western equine encephalatis. Am. J. Trop. Med. Hyg. 4, 106-118.

Christe, P., Richner, H. and Oppliger, A. (1996). Begging, food provisioning, and nestling competition in great tit broods infested with ectoparasites. Behav. Ecol. 7, 127-131.

Cornell, A., Gibson, K. F. and Williams, T. D. (2017). Physiological maturity at a critical lifehistory transition and flight ability at fledging. Funct. Ecol. 31, 662-670.

Cuervo, J. J., Møller, A. P. and De Lope, F. (2007). Haematocrit is weakly related to condition in nestling Barn Swallows Hirundo rustica. Ibis (Lond. 1859). 149, 128-134.

Drabkin, D. L. and Austin, J. H. (1932). Spectrophotometric studies. J. Biol. Chem. 98, 719733.

Feare, C. (1984). The Starling. Oxford: Oxford University Press.

Fitze, P. S., Clobert, J. and Richner, H. (2004). Long-term life-history consequences of ectoparasite-modulated growth and development. Ecology 85, 2018-2026.

Ginsberg, B. H. (2009). Factors affecting blood glucose monitoring: sources of errors in measurement. J. Diabetes Sci. Technol. 3, 903-13.

Gwinner, H., Oltrogge, M., Trost, L. and Nienaber, U. (2000). Green plants in starling nests: effects on nestlings. Anim. Behav. 59, 301-309.

Hasselquist, D. and Nilsson, J. Å. (2012). Physiological mechanisms mediating costs of immune responses: What can we learn from studies of birds? Anim. Behav. 83, 1303-1312. 
Heeb, P., Kölliker, M. and Richner, H. (2000). Bird - ectoparasite interactions, nest humidity, and ectoparasite community structure. Ecology 81, 958-968.

Hund, A. K., Blair, J. T. and Hund, F. W. (2015). A review of available methods and description of a new method for eliminating ectoparasites from bird nests. J. F. Ornithol. 86, 191-204.

Immediato, D., Figueredo, L. A., Iatta, R., Camarda, A., de Luna, R. L. N., Giangaspero, A., Brandão-Filho, S. P., Otranto, D. and Cafarchia, C. (2016). Essential oils and Beauveria bassiana against Dermanyssus gallinae (Acari: Dermanyssidae): Towards new natural acaricides. Vet. Parasitol. 229, 159-165.

Johnson, L. S. and Albrecht, D. J. (1993). Effects of haematophagous ectoparasites on nestling House wrens, Troglodytes aedon: who pays the cost of parasitism? Oikos 66, 255-262.

Juráni, M., Výboh, P., Zeman, M., Lamošová, D., Košt’ál, L. and Blažíček, P. (2004). Posthatching dynamics of plasma biochemistry in free-living European starlings (Sturnus vulgaris). Comp. Biochem. Physiol. - A Mol. Integr. Physiol. 138, 89-95.

Kim, S. Il, Yi, J. H., Tak, J. H. and Ahn, Y. J. (2004). Acaricidal activity of plant essential oils against Dermanyssus gallinae (Acari: Dermanyssidae). Vet. Parasitol. 120, 297-304.

King, M. O., Owen, J. P. and Schwabl, H. (2011). Injecting the mite into ecological immunology: measuring the antibody response of house sparrows (Passer domesticus) challenged with hematophagous mites. Auk 128, 340-345.

Kitaysky, A. S., Wingfield, J. C. and Piatt, J. F. (2001). Corticosterone facilitates begging and affects resource allocation in the black-legged kittiwake. Behav. Ecol. 12, 619-625. 
Lambrechts, M. M., Stenning, M. J., Adriaensen, F., Ardia, D. R., Artemyev, A. V., Atiénzar, F., Bańbura, J., Barba, E., Bouvier, J.-C., Camprodon, J., et al. (2010). The design of artificial nestboxes for the study of secondary hole-nesting birds: A review of methodological inconsistencies and potential biases. Acta Ornithol. 45, 1-26.

Lesna, I., Wolfs, P., Faraji, F., Roy, L., Komdeur, J. and Sabelis, M. W. (2009). Candidate predators for biological control of the poultry red mite Dermanyssus gallinae. Exp. Appl. Acarol. 48, 63-80.

Lindström, K. M., Foufopoulos, J., Pärn, H. and Wikelski, M. (2004). Immunological investments reflect parasite abundance in island populations of Darwin's finches. Proc. Biol. Sci. 271, 1513-9.

López-Arrabé, J., Cantarero, A., Pérez-Rodríguez, L., Palma, A. and Moreno, J. (2014). Experimental pyrethroid treatment underestimates the effects of ectoparasites in cavitynesting birds due to toxicity. Ibis (Lond. 1859). 156, 606-614.

MacDonald, I. F., Kempster, B., Zanette, L. and MacDougall-Shackleton, S. A. (2006).

Early nutritional stress impairs development of a song-control brain region in both male and female juvenile song sparrows (Melospiza melodia) at the onset of song learning. Proc. Biol. Sci. 273, 2559-2564.

Maxwell, M. (1993). Avian blood leucocyte responses to stress. Worlds. Poult. Sci. J. 49, 34-43.

Mazgajski, T. D. (2007). Effect of old nest material on nest site selection and breeding parameters in secondary hole nesters - a review. Acta Ornithol. 42, 1-14.

Merino, S. and Potti, J. (1995). Mites and blowflies decrease growth and survival in nestling pied flycatchers. Oikos 73, 95-103. 
Merino, S., Møller, A. and De Lope, F. (2000). Seasonal changes in cell-mediated immunocompetence and mass gain in nestling barn swallows: a parasite-mediated effect? Oikos 90, 327-332.

Minias, P. (2015). The use of haemoglobin concentrations to assess physiological condition in birds: a review. Conserv. Physiol. 3, 1-15.

Møller, A. (1990). Effects of parasitism by a haematophagous mite on reproduction in the barn swallow. Ecology 71, 2345-2357.

Møller, A. P. (2002). Temporal change in mite abundance and its effect on barn swallow reproduction and sexual selection. J. Evol. Biol. 15, 495-504.

Moreno, J., Merino, S., Sanz, J., Arriero, E., Morales, J. and Tomas, G. (2005). Nestling mediated immune response, body mass and hatching data as predictors of local recruitment in the pied flycatcher, Ficedula hypoleuca. J. Avian Biol. 36, 251-260.

Moret, Y. and Schmid-Hempel, P. (2000). Survival for immunity: The price of immune system activation for bumblebee workers. Science 290, 1166-1168.

Morrison, K. W., Hipfner, J. M., Gjerdrum, C. and Green, D. J. (2009). Wing length and mass at fledging predict local juvenile survival and age at first return in tufted puffins. Condor 111, 433-441.

Naguib, M., Riebel, K., Marzal, A. and Gil, D. (2004). Nestling immunocompetence and testosterone covary with brood size in a songbird. Proc. Biol. Sci. 271, 833-8.

Naguib, M., Nemitz, A. and Gil, D. (2006). Maternal developmental stress reduces reproductive success of female offspring in zebra finches. Proc. R. Soc. London B Biol. Sci. 273, 19011905. 
Nowicki, S., Peters, S. and Podos, J. (1998). Song learning, early nutrition and sexual selection in songbirds. Am. Zool. 38, 179-190.

Owen, J. C. (2011). Collecting, processing, and storing avian blood: A review. J. F. Ornithol. 82, 339-354.

Owen, J. P., Mullens, B. A., Justus, K. A. and Carde, R. T. (2005). Northern fowl mite orientation in a thermal gradient and evidence for idiothetic course control. Physiol. Entomol. 30, 293-302.

Owen, J. P., Delany, M. E., Cardona, C. J., Bickford, A. A. and Mullens, B. A. (2009). Host inflammatory response governs fitness in an avian ectoparasite, the northern fowl mite (Ornithonyssus sylviarum). Int. J. Parasitol. 39, 789-799.

Petit, C., Hossaert-McKey, M., Perret, P., Blondel, J. and Lambrechts, M. M. (2002). Blue tits use selected plants and olfaction to maintain an aromatic environment for nestlings. Ecol. Lett. 5, 585-589.

Pirrello, S., Pilastro, A. and Serra, L. (2015). Nest-dwelling ectoparasites influence the start and duration of the first pre-basic moult in the European starling Sturnus vulgaris. J. Avian Biol. 46, 001-007.

Proctor, H. and Owens, I. (2000). Mites and birds: Diversity, parasitism and coevolution. Trends Ecol. Evol. 15, 358-364.

Pryor, L. J. and Casto, J. M. Ectoparasite-induced trade-offs in somatic and physiological development. J. Exp. Zool. 201X,.

Pryor, L. J. and Casto, J. M. (2015). Blood-feeding ectoparasites as developmental stressors: Does corticosterone mediate effects of mite infestation on nestling growth, immunity, and energy availability? J. Exp. Zool. 323A, 466-477. 
Remage-Healey, L. and Romero, L. M. (2002). Corticosterone and insulin interact to regulate plasma glucose but not lipid concentrations in molting starlings. Gen. Comp. Endocrinol. 129, 88-94.

Rendell, W. B. and Verbeek, N. A. M. (1996). Are avian ectoparasites more numerous in nest boxes with old nest material? Can. J. Zool. 74, 1819-1825.

Saino, N., Calza, S., Møller, A. P. and Moller, A. P. (1998). Effects of a dipteran ectoparasite on immune response and growth trade-offs in barn swallow, Hirundo rustica, nestlings. Oikos 81, 217.

Samani, A. D., Ghahfarokhi, S. M. and Samani, A. D. (2014). An invivo survey on effect of essential oil of Achillea millefolium on wound healing in chicken (geometrical study). J. Nat. Remedies 14, 93-97.

Shutler, D. and Campbell, A. A. (2007). Experimental addition of greenery reduces flea loads in nests of a non-greenery using species, the tree swallow Tachycineta bicolor. J. Avian Biol. 38, 7-12.

Sikes, R. K. and Chamberlain, R. W. (1954). Laboratory observations on three species of bird mites. J. Parasitol. 40, 691-697.

Smith, K. D. and Barber, C. A. (2012). Hematocrit does not indicate condition in nestling or adult European starlings. Wilson J. Ornithol. 124, 788-792.

Strasser, E. H. and Heath, J. A. (2013). Reproductive failure of a human-tolerant species, the American kestrel, is associated with stress and human disturbance. J. Appl. Ecol. 50, 912919. 
Tauk, B. S., Drobatz, K. J., Wallace, K. A. and Hess, R. S. (2015). Correlation between glucose concentrations in serum, plasma, and whole blood measured by a point-of-care glucometer and serum glucose concentration measured by an automated biochemical analyzer for canine and feline blood samples. J. Am. Vet. Med. Assoc. 246, 1327-1333.

Tomás, G., Merino, S., Moreno, J. and Morales, J. (2007). Consequences of nest reuse for parasite burden and female health and condition in blue tits, Cyanistes caeruleus. Anim. Behav. 73, 805-814.

Tripet, F. and Richner, H. (1997). Host responses to ectoparasites: Food compensation by parent blue tits. Oikos 78, 557-561.

Tschirren, B., Richner, H. and Schwabl, H. (2004). Ectoparasite-modulated deposition of maternal androgens in great tit eggs. Proc. R. Soc. B Biol. Sci. 271, 1371-5.

Veiga, J. A. S., Roselino, E. S. and Migliorini, R. H. (1978). Fasting, adrenalectomy, and gluconeogenesis in chicken and a carnivorous bird. Am. J. Physiol. Integr. Comp. Physiol. 234, R115-R121.

Williams, T. D., Fronstin, R. B., Otomo, A. and Wagner, E. (2012). Validation of the use of phenylhydrazine hydrochloride (PHZ) for experimental manipulation of haematocrit and plasma haemoglobin in birds. Ibis (Lond. 1859). 154, 21-29.

Wimberger, P. H. (1984). The use of green plant material in bird nests to avoid ectoparasites. Auk 101, 615-618.

Wingfield, J. C., Smith, J. P. and Farner, D. S. (1982). Endocrine responses of white-crowned environmental stress sparrows to environmental stress. Condor 84, 399-409. 


\section{Figures}

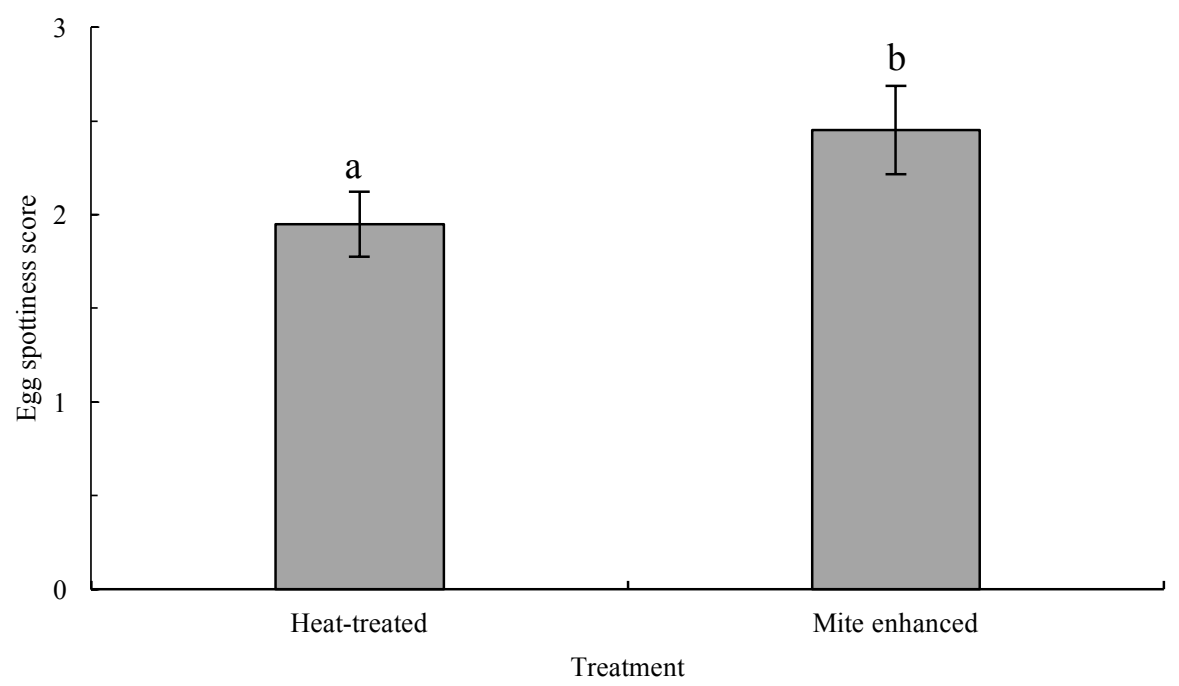

Figure 1. Egg spottiness score across experimental treatments. MRBL $(n=8)$ and $M R(n=18)$ treatments were condensed into heat-treated group, then contrasted against the $\mathrm{ME}(\mathrm{n}=14)$ treatment. Least square means $( \pm$ SEM) of nests given. Different superscript letters indicate differences amongst treatments $(p<0.05)$. 


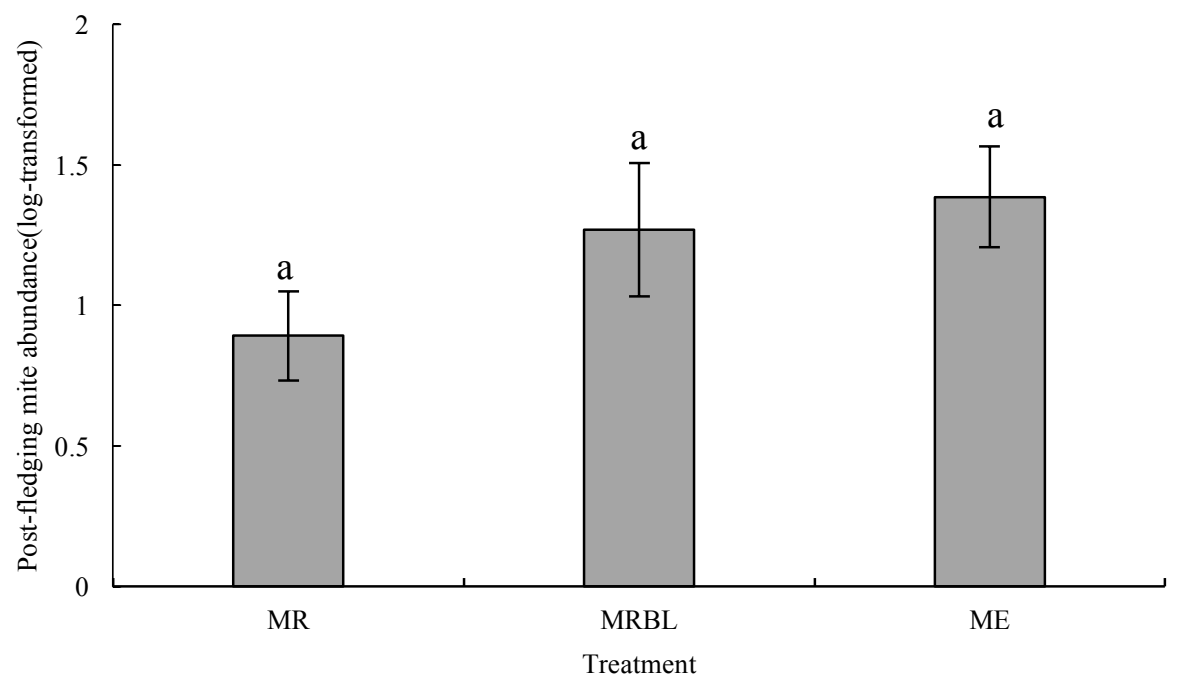

Figure 2. Post-fledging mite abundance across experimental treatments. Least square means ( \pm SEM, log-transformed) of mite samples taken from MR $(n=18), \operatorname{MRBL}(n=8)$ and ME $(n=14)$ nests. Different superscript letters indicate differences amongst treatments $(\mathrm{p}<0.05)$. 


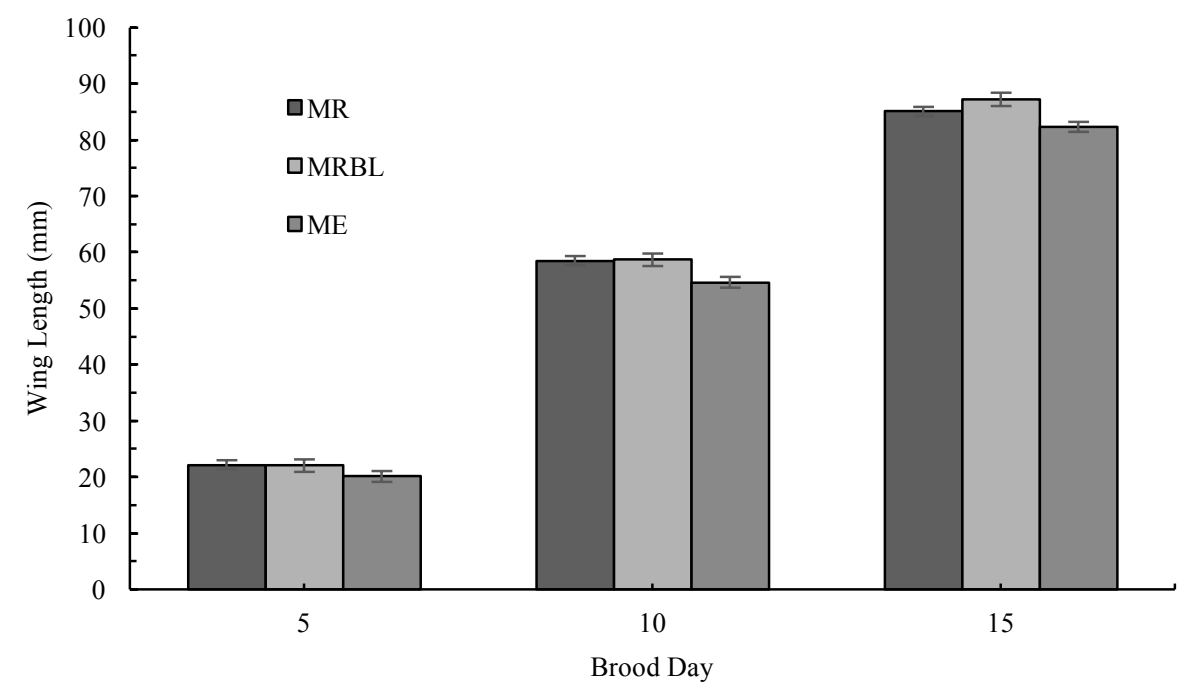

Figure 3. Effects of experimental treatments on wing length across development. Least square means $(\mathrm{mm} \pm \mathrm{SEM})$ of nestling wing length for MR $(\mathrm{n}=18), \operatorname{MRBL}(\mathrm{n}=10)$ and ME $(n=13)$ treatments. Values averaged within nests on BDs 5, 10 and 15. 
A
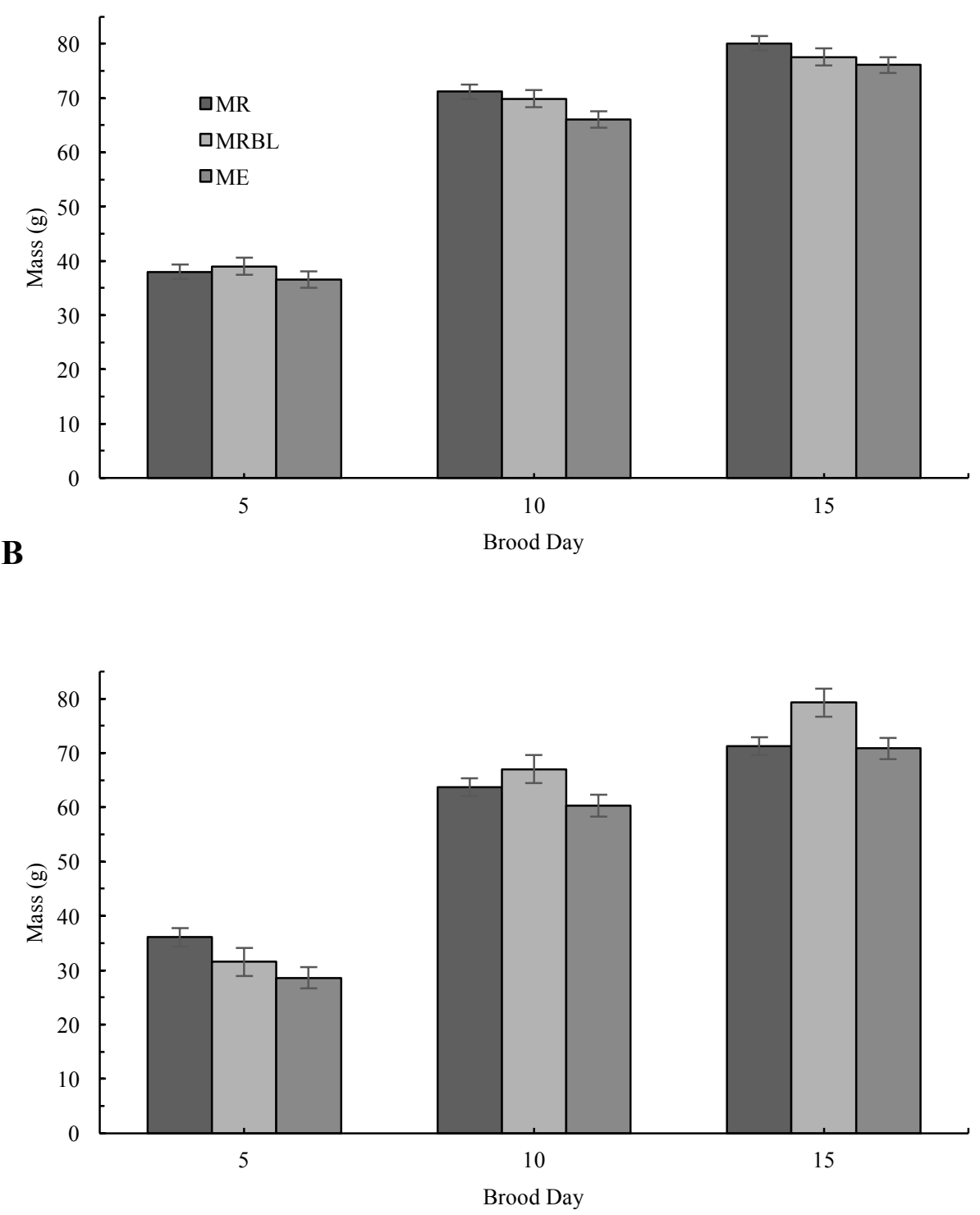

Figure 4. Effects of experimental treatments on mass across development. Least square means of nestling mass $(\mathrm{g} \pm$ SEM) across MR $(\mathrm{n}=18)$, MRBL $(\mathrm{n}=11)$ and ME $(\mathrm{n}=14)$ nests. Separated by (A) Early-season broods and (B) Late-season broods. Values averaged within nests on BD 5, 10 and 15 . 


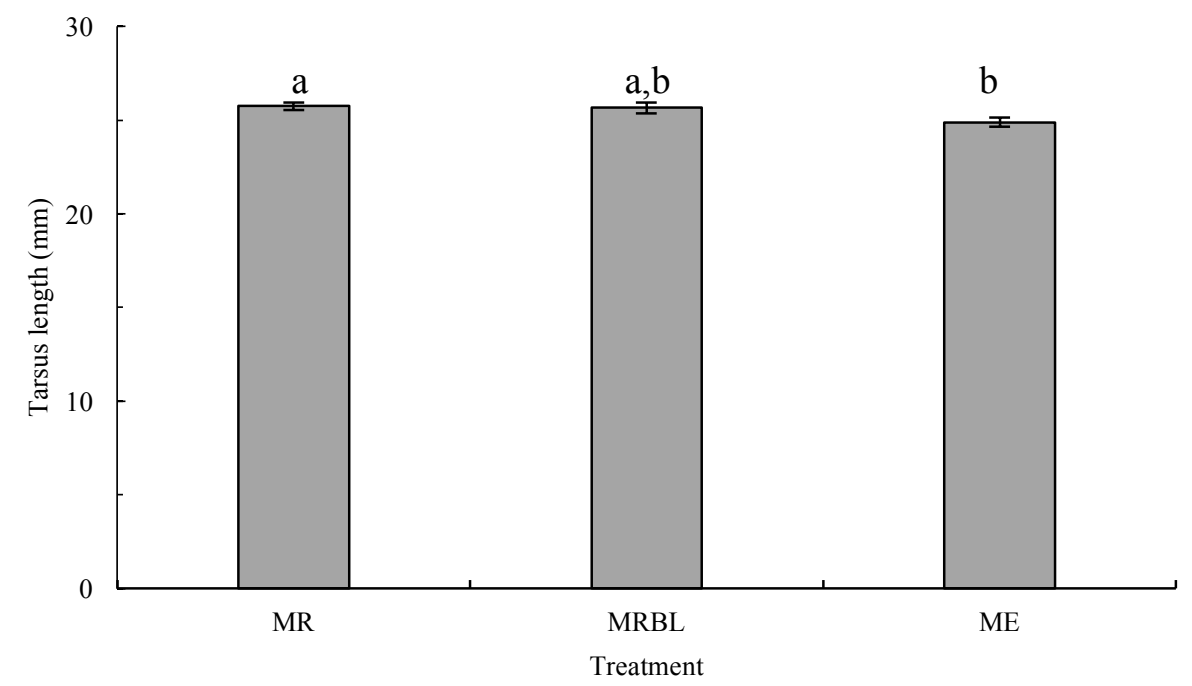

Figure 5. Effects of experimental treatments on tarsus length between treatments. Least square means of tarsus length $(\mathrm{mm} \pm \operatorname{SEM})$ across MR $(\mathrm{n}=18), \operatorname{MRBL}(\mathrm{n}=11)$ and $\mathrm{ME}(\mathrm{n}=14)$ treatments. Different superscript letters indicate differences amongst treatments $(p<0.05)$. Values averaged within nests. 


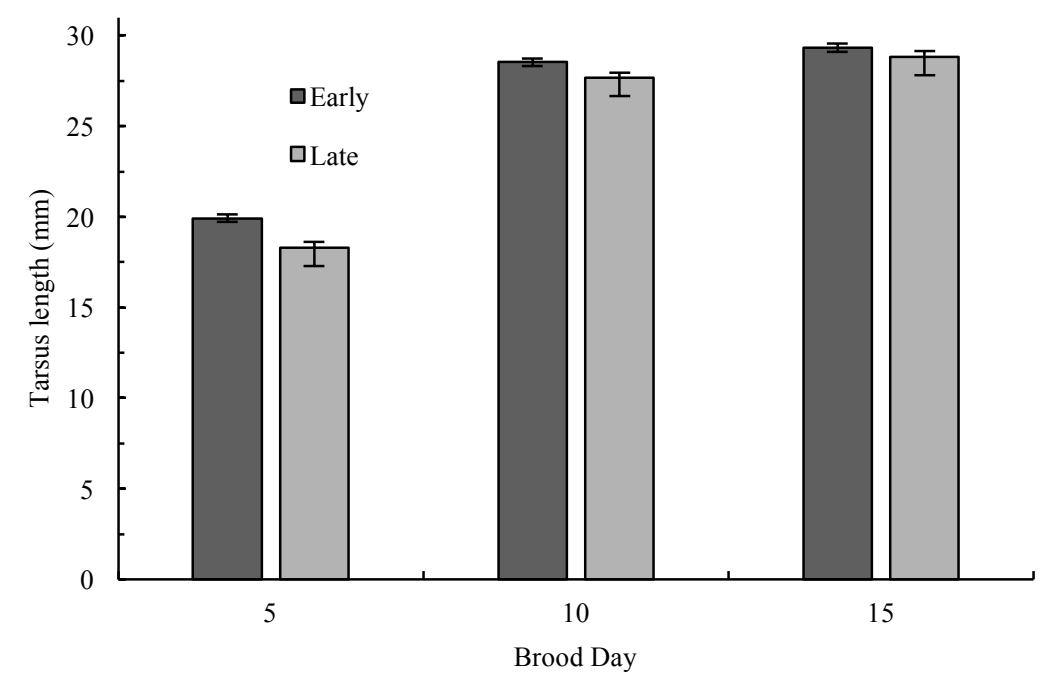

Figure 6. Effects of age and season on tarsus length. Least square means of tarsus length (mm \pm SEM) of early $(\mathrm{n}=28)$ and late-season $(\mathrm{n}=15)$ broods across BD 5, 10 and 15. Values averaged within nests. 
A

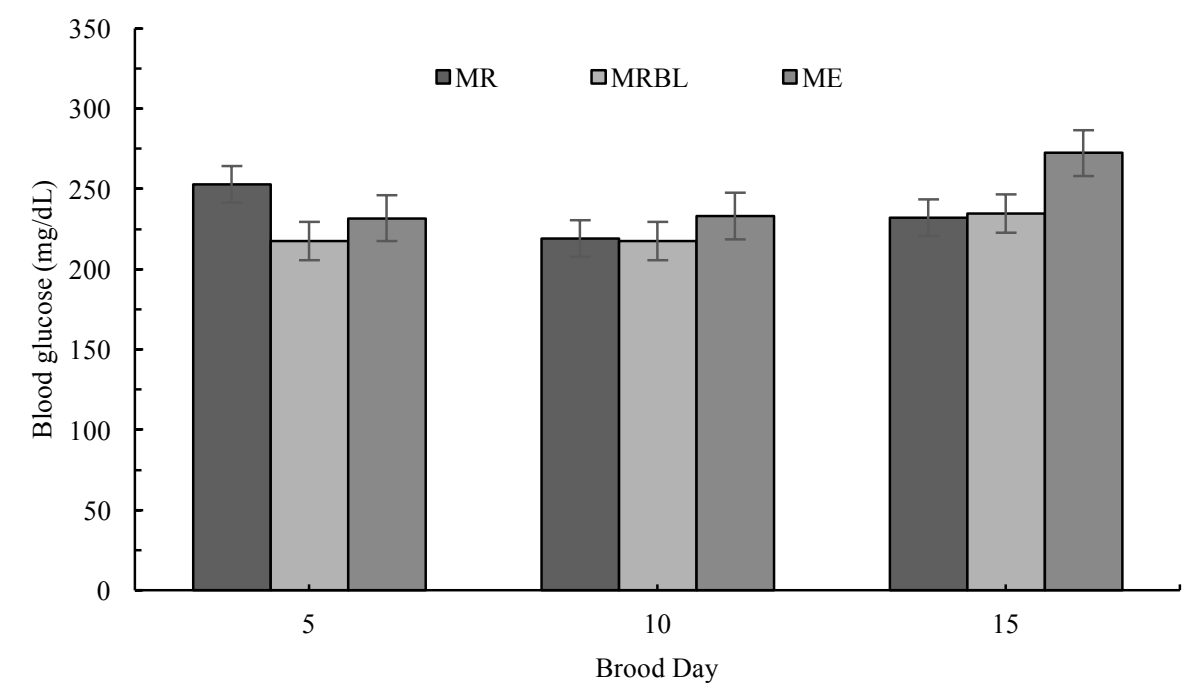

B

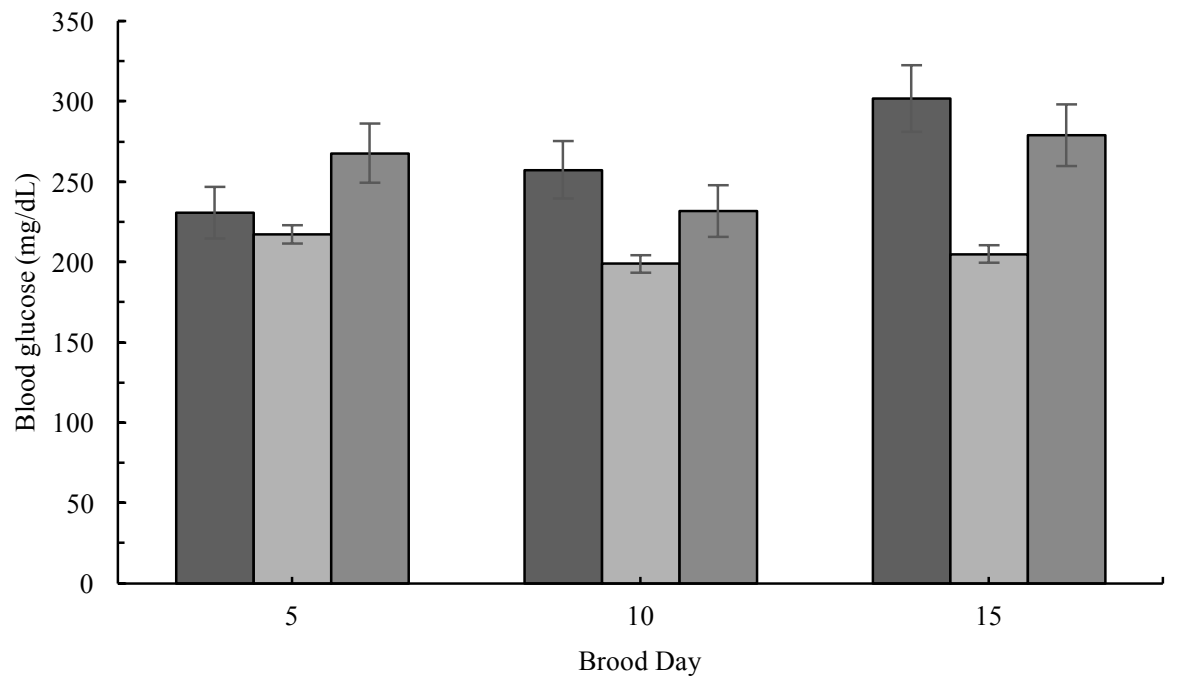

Figure 7. Effects of experimental treatments on blood glucose concentration across

development. Least square means of blood glucose concentration (mg/dL $\pm \mathrm{SEM}$ ) across MR $(\mathrm{n}=18), \operatorname{MRBL}(\mathrm{n}=11)$ and ME $(\mathrm{n}=14)$ nests. Separated by $(\mathrm{A})$ Early-season broods and (B) Late-season broods. Values averaged within nests on BD 5, 10 and 15. 

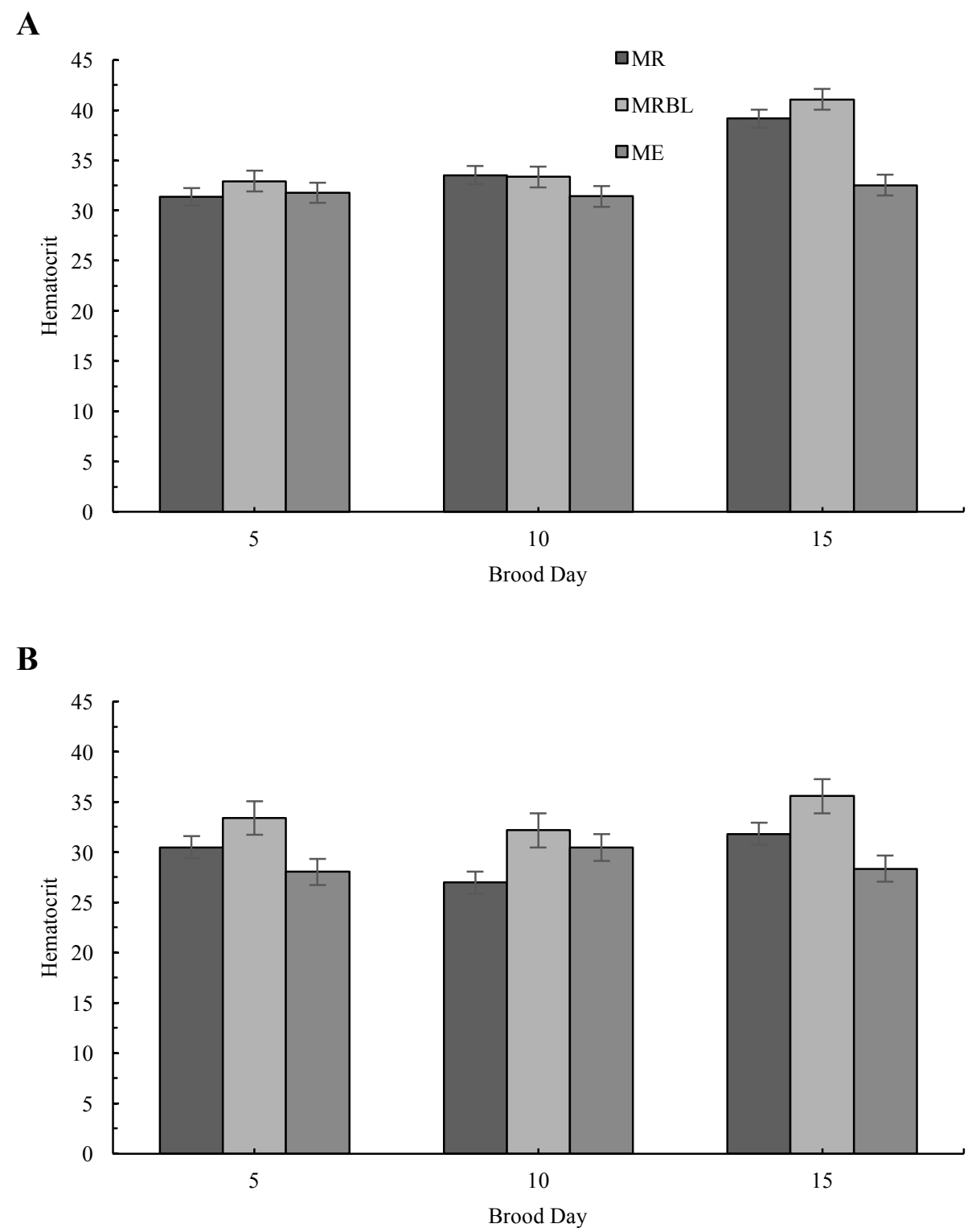

Figure 8. Effects of experimental treatments on hematocrit across development. Least square means of hematocrit volume (percentage \pm SEM) across MR $(n=18)$, MRBL $(n=11)$ and ME ( $\mathrm{n}=13)$ nests. Separated by (A) Early-season broods and (B) Late-season broods. Values averaged within nests on BD 5, 10 and 15 . 
A

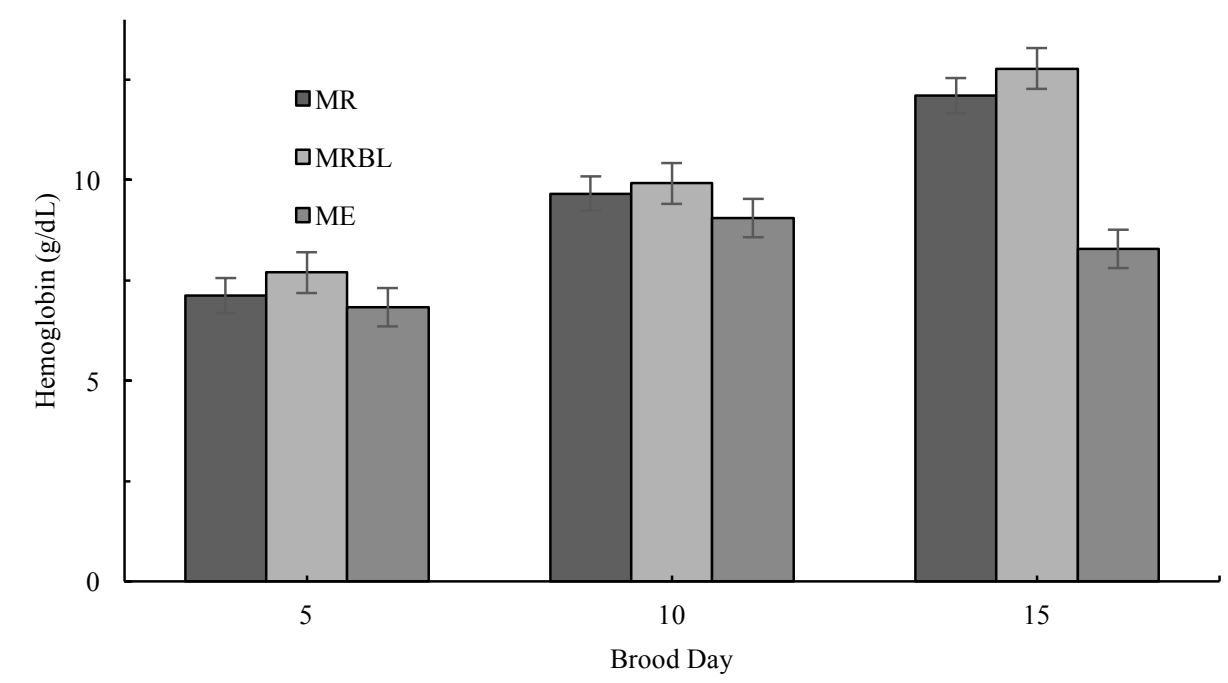

B

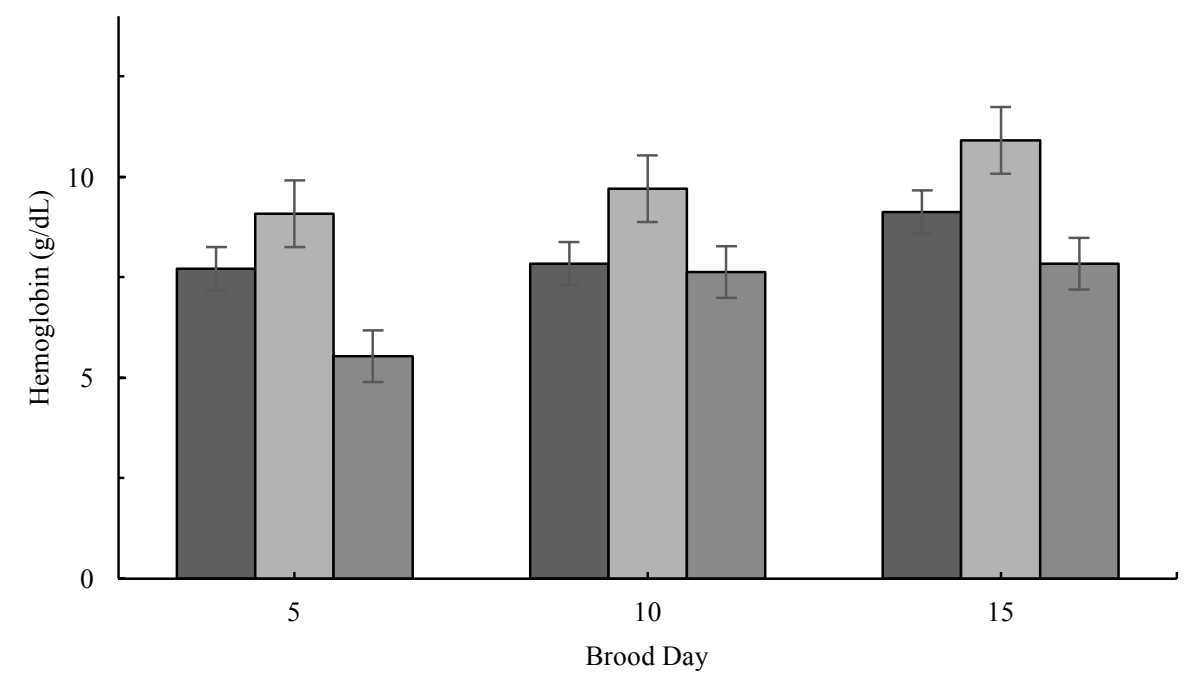

Figure 9. Effects of experimental treatments on hemoglobin across development. Least square means hemoglobin concentration ( $\mathrm{g} / \mathrm{dL} \pm$ SEM) across MR $(\mathrm{n}=18), \operatorname{MRBL}(\mathrm{n}=11)$ and ME ( $\mathrm{n}=13)$ nests. Separated by (A) Early-season broods and (B) Late-season broods. Values averaged within nests on BD 5, 10 and 15 . 


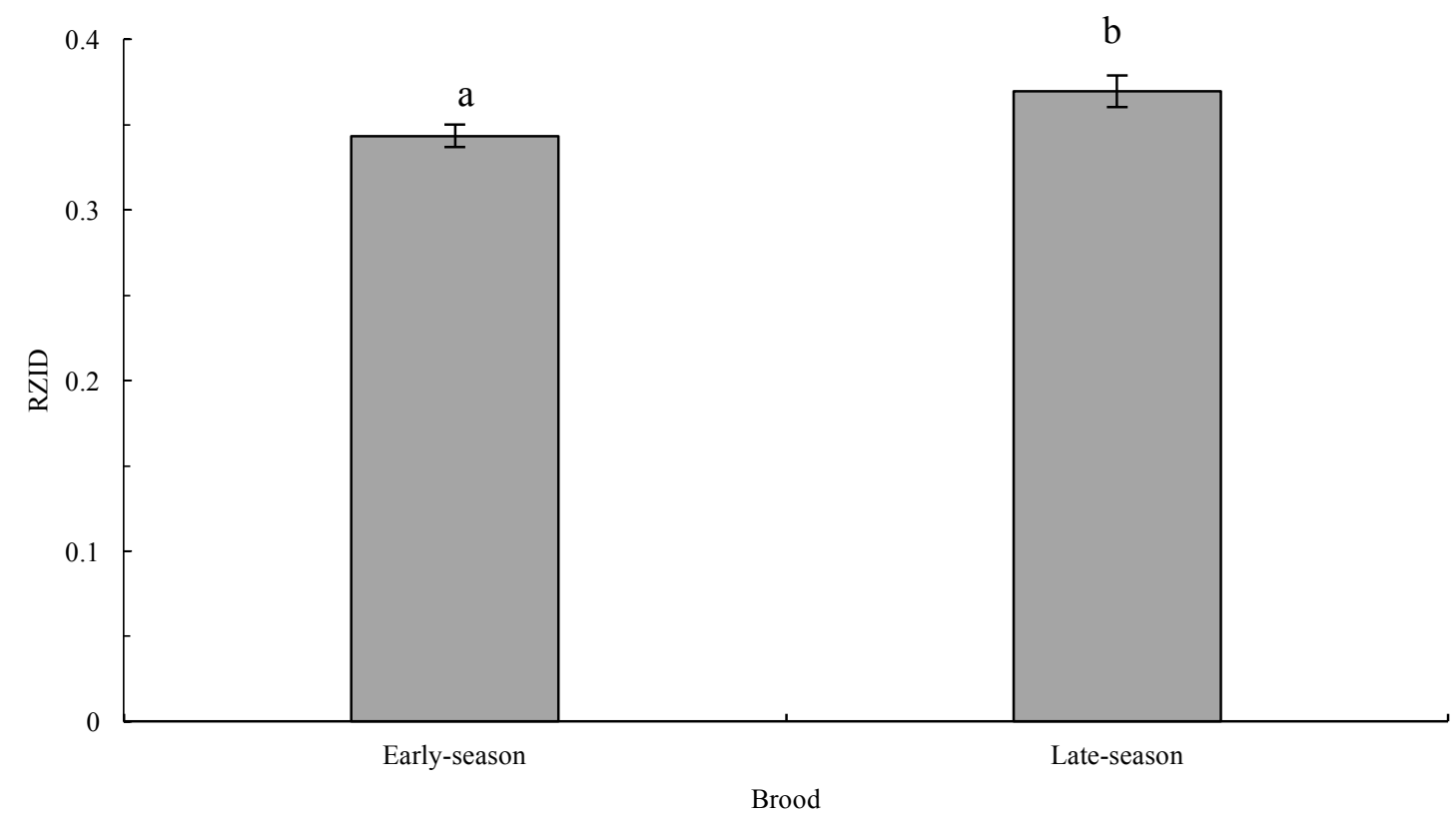

Figure 10. Seasonal effects on RZID. Least square means of RZID ( \pm SEM) in nests from early-season $(n=27)$ and late-season $(n=15)$ broods. Different superscript letters indicate differences among experimental treatments $(p<0.05)$. Values averaged within nests. 
CHAPTER II: THE EFFECTS OF ECTOPARASITE CONTROL METHODS ON MITE ABUNDANCE AND NESTLING PHENOTYPES 


\begin{abstract}
Developmental stressors are common in an organism's life history, and the energy loss/trade-offs that occur can lead to altered adult phenotypes. One common type of stressor that organisms have to contend with are ectoparasites, which commonly take blood from their hosts, as well as transfer antigens to trigger an immune response. The effects of ectoparasitism on developing organisms are of great interest, and often these studies hinge on being able to consistently manipulate ectoparasite abundance between experimental treatments. However, there is no perfect method of reducing their number, as one may have to balance the efficacy of the experimental treatment with any potential side effects suffered by the subjects. The literature describes several methods that vary in their efficacy for reducing ectoparasites in nests, as well as in their ectoparasite-independent effects on nestling development. This experiment assessed both the effectiveness of several control methods for hematophagous mite abundance in starling nests, and their effects on nestling development. After clutch completion, nests were inoculated with $\approx 100$ Northern fowl mites (Ornithonyssus sylviarum) to simulate an infestation. To assess mite abundance prior to mite control treatment, blood spots on the eggs were evaluated 10 days after clutch completion. On the nest hatch date, nests were placed into one of four mite control treatments: control, heat, yarrow oil, and permethrin. These nest treatments were applied at hatching and again 10 days later. Nestling growth was assessed 5, 10 and 15 days after hatch. Blood was collected 15 days post-hatch to analyze hematocrit, hemoglobin and blood glucose concentrations. Nests in permethrin-treated nests had the least amount of mites, but displayed lower blood glucose concentrations, and higher hematocrit levels than nestlings in the control treatment. Nestlings in heat-treated nests had an increased number of hematophagous mites on their body compared to the other treatment groups. Our results showed that pesticide treatments
\end{abstract}


could hinder nestling development to that of mite-infested nestlings. As well, heat treatments may actually improve the nest environment for ectoparasites, leading to increased parasitism in the nest and more severe developmental deficiencies.

\section{INTRODUCTION}

Parasitism is a common ecological stressor faced by wild animals, reducing their available resources and altering their phenotypes (Møller, 2002; Nowicki et al., 1998). Cavity nesting passerines tend to run the risk of parasitism, as they are often subject to ectoparasites in their nests (Heeb et al., 2000; Tomás et al., 2007). Ectoparasites like mites and fleas have been shown to parasitize adults and young in the nest, and their presence can lead to impaired reproductive success (Møller, 1990), growth (Tomás et al., 2007), and increased mortality (Møller, 1990).

As many studies have shown, ectoparasite infestation can lead to negative effects on pre and post-hatching development (Fitze et al., 2004; Pryor and Casto, 2015; Tschirren et al., 2004), thus it is common to experimentally manipulate mite abundance in nests to study their impact on nestling development (Brown et al., 1995). However, there is no "optimal” approach to reducing mite abundance in nests, as different experimental treatments have varying levels of effectiveness and potential side effects that they may have on nestling phenotypes (Hund et al., 2015).

One common method used in field studies are pesticides, specifically pyrethroids (Hund et al., 2015; Pryor and Casto, 2015; Tomás et al., 2007). They have been shown to have ectoparasite eradication rates up to $96 \%$, and are listed as non-toxic to adult birds (Hund et al., 2015), hence why it is a common method. However, recent studies have shown that the use of pyrethroids in nests can lead to decreased growth in nestlings (López-Arrabé et al., 2014) and increased 
baseline concentrations of corticosterone (Pryor and Casto, in preparation), which could indicate an increased stress response.

Another method is the use of natural pesticides. Many avian species, including European starlings, have been shown to incorporate certain green plants into their nests, which emit aromatic hydrocarbons (Petit et al., 2002; Proctor and Owens, 2000; Wimberger, 1984). It is hypothesized that these compounds have acaricidal properties, and that is the reason these birds may be incorporating the material in their nests (Wimberger, 1984). This has been tested multiple times, with some studies showing that these green plants are effective at removing ectoparasites from the nest (Shutler and Campbell, 2007), while others only seem to improve nestling condition as opposed to reducing mite abundance (Gwinner et al., 2000). One such plant that could be used for mite control is the common milfoil flower. Milfoil, also known as yarrow (Achillea millefolium) is a common aromatic flowering plant in North America, and starlings often incorporate them to their nests (Wimberger, 1984). Fresh milfoil can be woven into nest similar to how birds normally incorporate the material (Shutler and Campbell, 2007). To increase the concentration of volatile compounds found in the plants, commercially available oils could be substituted for fresh plant material. These oils have been used on adult chickens to stimulate wound healing at concentration up to $18 \%$ with no negative side effects (Samani et al., 2014), so using similar concentrations may not have any detrimental impacts on nestling development.

One newer method of reducing ectoparasites in nest material is exposing the nests to extremely high temperatures. This has been previously tested on Pied Flycatcher nests by using a microwave to reduce the number of mites, where they found that the treatment greatly reduced ectoparasite abundance (López-Arrabé et al., 2014). However, Pied Flycatcher nests are small, and the success of this treatment is not always effective at significantly reducing ectoparasites in 
other cavity-nesting species with much larger nests (Odetunde and Casto, in preparation; see also Chapter 1). An alternative way of applying heat is by using a commercially available heat gun (Hund et al., 2015). The nest is run over with the heat gun until the surface of the nest has reached the desired temperature, allowing a more thorough heating of the nest, although it is more time consuming than the microwave method, 24 hours after inoculating nests with mites, researchers heated the nests with the heat gun, resulting in up to $98 \%$ reduction in mite abundance, and no effects on nestling growth or mortality (Hund et al., 2015). With this high success in mite eradication, coupled with the lack of negative effects on nestling growth (Hund et al., 2015), this modified heat treatment method may prove to be a favorable option in ectoparasite management for the future.

In order to properly examine the repercussions of mite infestations on European starlings, the effects of common methods must be quantified, in order to gain a better understanding of how different experimental treatments can alter the interpretation of ectoparasite-induced effects on nestlings.

The goal of this experiment was to determine the efficacy of several possible methods of mite control in bird nests, while examining any side effects they may have on nestling development. This would help determine which methods have the highest degree of mite reduction, while quantifying any negative effects on the nestlings in future studies involving cavity-nesting birds. We hypothesized that the more effective a treatment is for controlling mites, the more negative effects it would have on nestling development. We predicted that the relative to alternative mite treatments, pesticide-treated nests would display the largest reductions in mite abundance, but that the nestlings suffer the most severe deficiencies in somatic growth, physiological development and immune function. 


\section{MATERIALS AND METHODS}

\section{Subjects, Study Site, and Ectoparasites}

This research was conducted during the 2016 breeding season on a population European starling nestlings raised by free-living adults in nest boxes (for nest box description see Pryor and Casto, 2015) at field sites in central Illinois. Adult starlings can raise up to two successful broods annually, and readily nest in man-made nest boxes (Feare, 1984). All vertebrate animal use in this research was in accordance with prevailing local, state, and federal standards and guidelines and approved by the Institutional Animal Use and Care Committee of Illinois State

University. All nests that commenced laying in the colonies between the $18^{\text {th }}$ of April and the $5^{\text {th }}$ of June, and that remained active until the treatments were initiated, were included in the study. At our experimental nest box colonies, the northern fowl mite (NFM), when present in nests, is the most abundant blood-feeding ectoparasite found in starling nests at our study sites (Pryor and Casto, 2015), and is a common ectoparasite in starling nests world-wide (Proctor and Owens, 2000). Mites were collected from the previous summer's old nest material, and were kept in the lab for later mite inoculation (see below).

\section{General Field Procedures and Study Design}

During the 2016 breeding season, nests were checked every three days for clutch initiation. Once at least one egg was found in the nest, the nests were checked daily until clutch completion. All nests then had $\approx 100$ NFM added to them to ensure each nest had at least a small mite infestation at the start of treatment, and were then alternately assigned to one of four experimental treatment groups: control (CONT), pesticide-treated (PEST), yarrow oil-treated (MILF) and heat-treated (HEAT). Nests were checked again 10 days later, which was approximately when incubation 
ended, and thereafter daily until hatching ceased. Once hatched, each hatchling had a different toenail clipped as a unique within-nest identifier. The day on which a majority of eggs had hatched was designated as the nest hatch date, or brood day (BD) 0 for the nest; however, individual hatch dates were also recorded to assess hatching asynchrony.

All nests underwent their respective experimental treatments on BD 0 and again on BD10. At these times, nestlings and unhatched eggs were removed from the nest and placed in an insulated container until the treatment application was finished. Nests were then carefully removed from the nest box to apply experimental treatments. Pesticide-treated nests were sprayed with $\approx 9 \mathrm{ml}$ of $0.1 \%$ Permethrin (Durvet; Blue Springs, Missouri), a pyrethroid, diluted from 10\% with distilled water, applied evenly to the top, bottom and each side of the nest. Likewise, yarrow oiltreated nests were sprayed with $\approx 9 \mathrm{ml}$ of the alcohol-free oil extract from the common yarrow flower (Achillea millefolium; Nature's Answer; New York, NY) diluted to a 10\% concentration with distilled water. Control nests were sprayed with $\approx 9 \mathrm{ml}$ of distilled water. Heat-treated nests had a heat gun (Wagner, HT3500, Minnesota) run over a nest until all external surfaces reached $100^{\circ} \mathrm{C}$, as measured with a laser-targeted infrared thermometer (Hypertough Infrared Thermometer; Glen Burnie, Maryland). Prior to replacing nests, the interiors of all nest boxes except those in the control group were swept with a stiff brush to remove debris and lingering ectoparasites.

In total, 125 nests had at least one starling egg laid in them during the course of the breeding season. Of those nests, 117 were active when egg laying ceased and incubation commenced. These nests received treatment assignments and were experimentally infested with NFM, to reduce the likelihood of non-infested nests in the study. At BD 0, when experimental mite reduction treatments commenced, there were 86 active nests (23 CONT, 23 HEAT, 21 MILF, 
and 19 PEST). Of these nests, 59 were active and received the second round of treatments on BD 10 (16 CONT, 14 HEAT, 15 MILF, and 14 PEST), and 53 (14 CONT, 14 HEAT, 12 MILF, and 13 PEST), had at least one nestling still alive at BD 15. The data from these 53 nests are included in this study.

\section{Mite Addition and Mite Burden Assessments}

Northern fowl mites (NFM) to be added to all nests were obtained from nesting material from the 2015 breeding season collected prior to the start of the 2016 breeding season. Approximately 100 mites (predominantly unfed protonymphs) were transferred to each new nest on the day following clutch completion. In order to assess mite burden in nests just prior to hatching, ten days after confirmed clutch completion, the starling eggs in all nests were visually checked for blood spots caused by blood-feeding ectoparasites biting the skin of incubating adults. Egg spottiness was ranked on a scale from 0-3 using modified methods of (Pryor and Casto, in review). A score of zero indicated an average of less than 1 blood spot/egg, a score of one indicated an average of $1-10$ blood spots/egg, a score of two indicated $11-50$ blood spots per egg, and a score of three indicated greater than 50 blood spots/egg. On the day of the second treatment $(\mathrm{BD} 10)$, as well as the day the nestlings fledged $(\approx \mathrm{BD} 21)$, we estimated the abundance of mites in the nest. On BD10, the mite abundance of each nestling was estimated using the same 0-3 scale previously used for egg spottiness (e.g. a spottiness score of 3 would mean $>50$ mites/nestling). When the nestlings had fledged, a sample of mites was collected from the nest for later quantification. Northern fowl mites, in the absence of a host, are attracted to warmth and increase locomotion in response to vibration (Owen et al., 2005). Hence, to collect a standardized sample of them from each nest, a warmed, reusable, water-filled, plastic ice cube 
measuring $\approx 2.5 \mathrm{~cm}^{3}$ was placed into the nest for $60 \mathrm{sec}$ to allow mites to discover and then crawl over it. The ice cube was then removed with forceps and immediately plunged into in a jar of $70 \%$ ethanol to kill and preserve any mites that had climbed upon it. Later, the contents of each jar were filtered and transferred to a grid-lined Petri dish for counting under a dissecting microscope. This technique has been used previously by our lab, and apparently samples only NFM from nests, as no other ectoparasites that are visible under 30x magnification have been identified despite counting over 664 ectoparasites from 43 nests. Based upon over 20 years of informal observation of mite activity in starling nests (Casto unpublished), we believe this sampling method takes advantage of a behavioral change in mites inhabiting recently vacated nests.

To assess whether ectoparasite samples collected using warmed reusable ice cubes are affected by ambient nest temperature, nest box temperatures were recorded during the collection of mites following fledging with a laser-targeted infrared thermometer aimed at the back of the nest box through the entrance hole and assessed for 5 seconds to get an accurate reading.

\section{Assessment of Somatic Growth}

On BDs 5, 10 and 15, the mass, wing length and tarsus length of each nestling was measured using an electronic balance, a metric wing ruler, and digital calipers, respectively. Additionally, on BD 10 all nestlings received a uniquely numbered U.S.G.S. aluminum leg band.

\section{Blood Collection and Processing}

Blood samples were collected via brachial venipuncture with a 26-gauge needle, into heparinized capillary tubes, and stored on ice until processed. On BD $15, \approx 250 \mu 1$ of blood was collected for 
later determination of hematocrit, hemoglobin concentration, plasma glucose concentration and plasma bactericidal ability. Stopwatches were used to record time of initial nest disturbance, time of each nestling's removal from nest, and time taken to bleed each nestling. Five $\mu$ l of whole blood was also preserved in $1.25 \mathrm{ml}$ of Drabkin's solution (Sigma-Aldrich, D5941) for later determination of hemoglobin concentration before blood flow was stanched with cotton. Blood was centrifuged at $13,300 \mathrm{rpm}(17,000 \mathrm{~g})$ for $10 \mathrm{~min}$, and plasma was harvested and its volume measured with a Hamilton syringe. Plasma was stored frozen at $-80^{\circ} \mathrm{C}$ in microcentrifuge tubes for later use in immunoassays.

\section{Blood Parameters}

Prior to plasma harvest, hematocrit was measured with a micro-capillary reader (model 220, Damon/IEC; Needham Heights, MA). Blood glucose concentration was assessed in both whole blood and plasma $(\approx 2 \mu \mathrm{l}$ of each) using a commercially available glucose reader and test-strips strips (ReliOn micro, Arkray USA, Edina, MN). Whole blood glucose concentration was measured in the field at the time of blood collection and fresh plasma was measured in the lab after nestling blood had been centrifuged and plasma had been harvested. Recent findings suggest that, when using commercial blood glucose monitors and test strips, plasma measurements may ensure greater accuracy than whole blood measurements (Tauk et al., 2015), which is why we wished to compare the methods. The whole blood preserved in Drabkin's reagent was used for quantification of hemoglobin concentration using the cyanmethemoglobin method (Drabkin and Austin, 1932) with absorbance measured at $540 \mathrm{~nm}$ on a microplate spectrophotometer (BioTek, Epoch; Bio-Tek Instruments, Winooski, VT, USA). 


\section{Assessment of Plasma Bactericidal Activity}

The bactericidal ability of plasma was quantified using a zone of inhibition assay modified from protocol by Moret and Schmid-Hempel (2000). DH5 $\alpha$ Escherichia coli was cultured at $37{ }^{0} \mathrm{C}$ in $6 \mathrm{~mL}$ of sterile broth medium $(5 \mathrm{~g}$ bacto-tryptone, $2.5 \mathrm{~g}$ yeast extract, $5 \mathrm{~g} \mathrm{NaCl}$ in $500 \mathrm{~mL}$ of distilled water, $\mathrm{pH} 7.5$ ) with $0.7 \%$ agar at $50{ }^{\circ} \mathrm{C} .300 \mu \mathrm{L}$ of chicken egg white in $1.0 \mathrm{M}$ PBS (100 $\mathrm{g} \mathrm{L}^{-1}$ ) was also added to aid in the lysis of $E$. coli. Ten wells were made in each plate with a Pasteur pipette, and $2 \mu \mathrm{L}$ of thawed and vortex-mixed, pure plasma samples were placed in eight of the wells. The remaining two wells contained a positive control $\left(25 \mu \mathrm{g} \mathrm{mL}^{-1}\right.$ gentamicin $)$ and a negative control (LB broth). Plates were placed upside down in an incubator at $40{ }^{\circ} \mathrm{C}$ for 24 hours. Petri dishes were then photographed using a magnifying HD digital video camera (Videoflex 7200HD; ken-a-vison, Kansas City, MO, USA) and the diameter of the zones of inhibition for each sample and the positive control were measured twice (horizontally and vertically) using digital image analysis software (Applied Vision 4; ken-a-vison, Kansas City, MO, USA). To quantify the immune response of individual nestlings, the average diameter of the zones of inhibition for each duplicate sample was divided by the average diameter of the positive control on the same dish, giving a relative zone of inhibition (RZID). RZIDs of duplicate samples were then averaged.

\section{Statistical Analysis}

Since the focus of this study was to analyze the effects of mite control treatments on traits that are reflective of post-fledging success of the starlings. Nests where no young survived to leave the nests would be unable to give us any insight into the sustained effects of these stressors. This 
is why we only chose to use nests where $\geq 1$ nestlings survived to fledging for statistical analyses.

Egg spottiness scores were analyzed across experimental treatments using a Kruskal-Wallis test to determine the similarity of mite abundance of the nests prior to the nests' first treatment. BD10 nestling mite scores were examined using a Kruskal-Wallis test to observe the effects of the mite control treatments 10 days after the first application. Post-fledging mite abundance was assessed using an analysis of covariance (ANCOVA), with one between subject's factor (treatment) and $\mathrm{BD} 0$ as the covariate. Nest temperature at mite collection was initially run as a covariate for this analysis, to take into account the mites' affinity for warmer temperatures and how that may have affected mite collection. That covariate turned out to be non-significant, so it was left out of the model. Brood reduction was analyzed using the proportion of nestlings failed within a nest.

When appropriate, dependent variables were averaged among nestlings within nests. Least square means were used for visualizing all analyses. Nestling wing length, tarsus length and mass were analyzed using repeated measures ANCOVAs, with one within subject's factor (age), one between subject's factor (treatment), and BD0 used as a covariate. Blood parameters (hematocrit, hemoglobin, blood glucose concentrations) and immune function were analyzed using ANCOVA, with treatment as a between subject's factor and BD0 as a covariate (plasma glucose analysis was run without BD0 to satisfy assumptions for the test). A regression was run to determine the correlation between whole blood and plasma glucose measurements. The following analyses used transformed data to conform to the assumptions of normality: final mite abundance (log-transformation), brood reduction (arcsin-transformation), wing length (square transformation), tarsus (fourth-power transformation), plasma glucose (log transformation), and 
the plasma vs. whole blood glucose regression (log-transformation). All statistical analyses were performed using SAS 9.4 software (SAS Institute Inc.; Cary, NC).

\section{RESULTS}

\section{Hatching_Asynchrony}

Of the 226 nestlings that hatched from the 53 nests reported here, $72.57 \%$ hatched on the same day as their first-hatched nest mate, $25.22 \%$ hatched one day later, $0.88 \%$ hatched two days later, $0.88 \%$ hatched 3 days later, and $0.44 \%$ hatched 5 days later.

\section{Brood Reduction}

There was a significant effect of nest hatch date on brood reduction $\left(F_{(1,48)}=10.07, p=0.0026\right)$, with nests hatching late in the season losing more nestlings than early season nests. There was no effect of treatment $\left(\mathrm{F}_{(3,48)}=0.18, \mathrm{p}=0.9067\right)$.

\section{Experimental Treatments and Measures of NFM Infestation}

There were no significant differences in egg spottiness scores among treatments $\left(\chi_{(3)}^{2}=3.2424, \mathrm{p}\right.$ $=0.3557$; Figure 1A). When examining the mite abundance on BD10, there was no significant effect of nest treatment $\left(\chi_{(3)}^{2}=6.8560, p=0.0766\right.$; Figure 1B). For post-fledging mite abundance, PEST nests yielded significantly fewer NFM during post-fledging sampling than the other three treatments $(F=5.61, p=0.0009$; Figure $1 C)$. There was no significant effect of BD0 on this parameter $(\mathrm{p}>0.05)$. 


\section{Growth}

The experimental treatments had no significant effect on nestling wing length $\left(\mathrm{F}_{(3,48)}=2.59, \mathrm{p}=\right.$ 0.0638). Nestling wing length increased with nestling age $\left(\mathrm{F}_{(2,98)}=3887.54, \mathrm{p}<0.0001\right)$, and decreased as they hatched later in the season $\left(\mathrm{F}_{(1,48)}=8.13, \mathrm{p}=0.0064\right)$. The interaction between treatment and nestling age $\left(\mathrm{F}_{(6,98)}=2.37, \mathrm{p}=0.0355\right)$ showed that CONT nestling wings were longer than HEAT nestling wings on BD $15(\mathrm{p}<0.03)$. Nestlings in the PEST treatment grew longer wings than HEAT nestlings on BD $10(\mathrm{p}<0.02)$, and both HEAT and MILF nestlings on BD 15 ( $\mathrm{p}<0.0003$ and $\mathrm{p}<005$, respectively; Figure 2). For tarsus, length was proportional to nestling age $\left(\mathrm{F}_{(2,98)}=1804.77, \mathrm{p}<0.0001\right)$. As for nestling mass, it increased with nestling age $\left(\mathrm{F}_{(2,98)}=1186.25, \mathrm{p}<0.0001\right)$, and nestlings hatched later in the season were lighter than early brood nestlings $\left(\mathrm{F}_{(1,48)}=38.79, \mathrm{p}<0.0001\right)$.

\section{Hematocrit, Hemoglobin and Blood Glucose Concentrations}

There were no significant effects of treatment and BD0 when analyzing whole blood glucose concentration $\left(\mathrm{F}_{(4,47)}=1.45, \mathrm{p}=0.2323\right)$, nor was there a significant effect of treatment on plasma glucose concentrations $\left(\mathrm{F}_{(3,48)}=1.64, \mathrm{p}=0.1925\right)$. When examining the relationship between whole blood and plasma glucose concentrations, we found that there was no significant correlation between these measurements. $\left(\mathrm{F}_{(1,50)}=0.12, \mathrm{p}=0.7255\right.$; Figure 3$)$. Hematocrit volume varied significantly among treatments $\left(\mathrm{F}_{(4,45)}=0.0043, \mathrm{p}=0.0062\right.$; Figure 4A), with CONT nestlings having lower hematocrit volume than the PEST nestlings $(p<0.01)$. As well, hematocrit was inversely proportional to the nest hatch date $(p=0.0005)$. We found a significant effect of treatment on hemoglobin $\left(\mathrm{F}_{(3,47)}=4.86, \mathrm{p}=0.005\right.$; Figure 4B), with CONT and HEAT nestlings having lower hemoglobin concentrations than PEST nestlings $(\mathrm{p}<0.02$ and $\mathrm{p}<0.01$, 
respectively). There was also a significant effect of nest hatch date $\left(\mathrm{F}_{(1,47)}=15.05, \mathrm{p}=0.0003\right)$, where nestlings that hatched later in the breeding season had lower hemoglobin concentrations.

\section{Plasma Bactericidal Activity}

There was no significant effect of treatment on plasma bactericidal activity, but there was an effect of nest hatch date $\left(\mathrm{F}_{(1,47)}=29.81, \mathrm{p}<0.0001\right)$, with nestlings hatching later in the breeding season displaying greater immune function than those that hatched earlier in the season.

\section{DISCUSSION}

The main objective of this experiment was to determine the efficacy of mite control methods, while also examining any side effects of said treatments on nestling development. We found that only the pesticide-treated nests had a significantly decreased post-fledging mite abundance relative to the control nests. Nestlings in pesticide-treated nests displayed no difference in growth parameters relative to nestlings in control nests, but did exhibit higher hemoglobin and hematocrit than control nestlings. Nestlings in heat-treated nests had shorter wings than nestlings in control and pesticide nests late in development, and lower hemoglobin than pesticide treated nestlings. The milfoil treatment yielded no differences in mite abundance and nestling development compared to control nestlings, but they had shorter wings than pesticide-treated nestlings late in development. Treatments also had no effect on the bactericidal ability of nestling plasma. These results suggest that the use of pesticides in starling nests does dampen nestling development while also being the most effective at reducing mite abundance. 


\section{Mite Control Efficacy}

As we predicted, the pesticide treatment was the most effective at eliminating mites from the nest by the time the nestlings fledged. Considering all of the nests had similar levels of miteabundance before treatment was applied, according to the egg spottiness scores, it stands to reason that these effects were not due to large variations in initial mite abundance. The heat and milfoil treatments tended to have the same amount of mites, so it appears that they are not very effective as mite removal methods. The milfoil treatment's effectiveness may be linked to the fact that essential oils alone are not enough to control the amount of ectoparasites. A study investigating the acaricidal ability of different essential oils and Beauvaria bassiana fungi found that a combination of the fungi and the essential oils increased the mortality rate of poultry red mites, as opposed to each component separately (Immediato et al., 2016). Essential oils are fairly volatile and dissipate quickly (Kim et al., 2004), so another issue with the milfoil treatment may have been the frequency of application was insufficient in controlling the mite abundance of the nest. Previous experience in the lab has shown that increased rates of nest disturbances increased the probability of nest abandonment (Casto, unpublished), thus an acaricidal treatment that needs minimal application to remain effective across nestling development would be more ideal.

The lack of effect of the heat treatment on mite abundance in the nests may have been due to heating actually creating a more favorable environment for the mites. While Northern fowl mites are fairly common in cavity nests, they are not the only ectoparasites found in starling nests. Other mite species like the red poultry mite, Androlaelaps casalis, and house mites are often found in starling nests (Lesna et al., 2009). There are even other hematophagous predators like carnid flies which are common pests to starlings (Pirrello et al., 2015). Heating the nest may 
negatively impact other nest factors that hinder the success of NFM, allowing them to thrive in the nest.

\section{Somatic Growth}

While the pesticide treatment did not display decreased growth compared to the control treatment, the fact that they had a considerably lower mite abundance while still showing similar growth patterns suggests that the Permethrin was causing developmental deficiencies in nestlings. As they were exposed to less mites than the other treatment groups, they were free of the previously observed effects of high mite abundance on wing length, tarsus length and mass (see Chapter 1). Those parameters being equal to control nestlings with a much higher mite abundance corroborates the results on the aforementioned López-Arrabé et al. (2014) that the use of pesticides, while effective for mite control, would result in underestimating the effects of ectoparasites on nestling development.

There is also a possibility that the some of the negative effects of pesticides in the nest were masked due to altered behavior of the nestlings and adults. Previous research has demonstrated that nestlings exposed to pesticides display higher baseline levels of corticosterone than nests without a pesticide treatment (Pryor and Casto, in review). Corticosterone is a hormone released by the pituitary glands (Veiga et al., 1978) and is released when an organism encounters stressors (Boonstra, 2004; MacDonald et al., 2006; Wingfield et al., 1982). Research on adult and nestling black-footed kittiwakes given corticosterone implants showed that the nestlings increased their feeding rates, and the adults spent more time away from the nest, possibly to increase foraging (Kitaysky et al., 2001). While the pesticide treatment may have had detrimental effects on nestling development, there is a possibility that the nestlings and adult starlings adjusted their 
behaviors to alleviate any potential complications. Thus, there is a possibility that the impacts of the Permethrin treatment in this study have been underestimated. Observing the feeding rates and begging behavior of pesticide-treated nests would give insight into whether the treatment alters parental and nestling behavior in starlings.

\section{Blood}

The lack of effect of treatment on blood glucose may show that the developmental shortcomings of the pesticide treated group were not due to a stress response. When birds are stressed, the HPA axis is activated, culminating in the release of corticosterone and increased blood glucose concentration (Remage-Healey and Romero, 2002). Pesticide-treated nestlings showing no change in blood glucose concentration may indicate that exposure to Permethrin does not stimulate the stress response in the nestlings.

The non-significant relationship between whole blood and plasma glucose measurements calls into question the most accurate way of evaluating blood glucose on nestlings. The lack of correlation between the two measurements shows that they cannot be used interchangeably when describing glucose concentrations, so these methods need to be further analyzed to determine which is more accurate. One of the explanations behind this discrepancy in whole blood and plasma measurements may be hematocrit concentrations. Blood cells have their own intracellular glucose concentrations, and extremely high or low hematocrit volumes can increase the error rate of glucose reagent strips (Ginsberg, 2009). Comparing the plasma and whole blood measurements with the glucometer against a glucose assay kit could determine which method is most accurate. 
As in a previous experiment, there was a seasonal effect on immune function, with nestlings hatched later in the breeding season having larger relative zones of inhibition. This effect can be a combination of increased mite abundance as the breeding season goes along, as well as decreased food availability for late brood nestlings (Merino et al., 2000). To determine if the effect is the result of food availability, observing parental provisioning may show how early and late brood parents differ in terms of size of food brought to the nest, number of visits, the quality of the food brought to the nest, etc.

In conclusion, Permethrin treatments may lead to some developmental deficiencies in starling nestlings, despite having a significant effect on mite abundance. The milfoil and heat treatment did not have any effect of mite abundance, so they are not favorable methods to use for future studies. The use of a heat treatment may also create a more favorable environment for the NFM. Glucose measurements require further inspection to ensure the most accurate method is implemented in future studies. Analysis on alternative mite control methods is needed to minimize mite abundance while avoiding negative effects on nestling development.

\section{Acknowledgements}

Thanks to the lab mates and volunteers who assisted me in the field, as well as in the lab, generating data. Thanks to Dr. Steve Juliano and Dr. Keith Bowers for statistical assistance. Thanks to the ISU Horticulture Center for the use of their facilities.

\section{Competing Interests}

No competing interests declared. 


\section{Funding}

Research was funded by the grants from the Phi Sigma Biological Honors Society, Beta Lambda Chapter, and the Illinois Ornithological Society to AO; and from the Center for Math, Science and Technology at Illinois State University and the Health Resources and Services Administration, Department of Health and Human Services (DHP 20062) to JMC. 


\section{LITERATURE CITED}

Badyaev, A. V, Hamstra, T. L., Oh, K. P. and Acevedo Seaman, D. A. (2006). Sex-biased maternal effects reduce ectoparasite-induced mortality in a passerine bird. Proc. Natl. Acad. Sci. U. S. A. 103, 14406-11.

Benard, M. F. (2004). Predator-induced phenotypic plasticty in organisms with complex life histories. Annu. Rev. Ecol. Syst. 35, 651-673.

Biard, C., Monceau, K., Motreuil, S. and Moreau, J. (2015). Interpreting immunological indices: The importance of taking parasite community into account. An example in blackbirds Turdus merula. Methods Ecol. Evol. 6, 960-972.

Boonstra, R. (2004). Coping with changing northern environments: the role of the stress axis in birds and mammals. Integr. Comp. Biol. 44, 95-108.

Bouslama, Z., Lambrechts, M. M., Ziane, N., Djenidi, R. D. and Chabi, Y. (2002). The effect of nest ectoparasites on parental provisioning in a north-African population of the Blue Tit Parus caeruleus. Ibis (Lond. 1859). 144, E73-E78.

Brown, C. R., Bomberger Brown, M. and Rannala, B. (1995). Ectoparasites reduce long-term survival of their avian host. Proc. R. Soc. B Biol. Sci. 262, 313-319.

Buchanan, K., Spencer, K., Goldsmith, A. and Catchpole, C. (2003). Song as an honest signal of past developmental stress in the European starling (Sturnus vulgaris). Proc. R. Soc. London B Biol. Sci. 270, 1149-1156.

Calbet, J. A. L., Lundby, C., Koskolou, M. and Boushel, R. (2006). Importance of hemoglobin concentration to exercise: Acute manipulations. Respir. Physiol. Neurobiol. 151, 132-140. 
Carleton, R. E. (2008). Ectoparasites affect hemoglobin and percentages of immature erythrocytes but not hematocrit in nestling Eastern Bluebirds. Wilson J. Ornithol. 120, 565568.

Chamberlain, R. W. and Sikes, R. K. (1955). Laboratory investigations on the role of bird mites in the transmission of eastern and western equine encephalatis. Am. J. Trop. Med. Hyg. 4, 106-118.

Christe, P., Richner, H. and Oppliger, A. (1996). Begging, food provisioning, and nestling competition in great tit broods infested with ectoparasites. Behav. Ecol. 7, 127-131.

Cornell, A., Gibson, K. F. and Williams, T. D. (2017). Physiological maturity at a critical lifehistory transition and flight ability at fledging. Funct. Ecol. 31, 662-670.

Cuervo, J. J., Møller, A. P. and De Lope, F. (2007). Haematocrit is weakly related to condition in nestling Barn Swallows Hirundo rustica. Ibis (Lond. 1859). 149, 128-134.

Drabkin, D. L. and Austin, J. H. (1932). Spectrophotometric studies. J. Biol. Chem. 98, 719733.

Feare, C. (1984). The Starling. Oxford: Oxford University Press.

Fitze, P. S., Clobert, J. and Richner, H. (2004). Long-term life-history consequences of ectoparasite-modulated growth and development. Ecology 85, 2018-2026.

Ginsberg, B. H. (2009). Factors affecting blood glucose monitoring: sources of errors in measurement. J. Diabetes Sci. Technol. 3, 903-13.

Gwinner, H., Oltrogge, M., Trost, L. and Nienaber, U. (2000). Green plants in starling nests: effects on nestlings. Anim. Behav. 59, 301-309.

Hasselquist, D. and Nilsson, J. Å. (2012). Physiological mechanisms mediating costs of immune responses: What can we learn from studies of birds? Anim. Behav. 83, 1303-1312. 
Heeb, P., Kölliker, M. and Richner, H. (2000). Bird - ectoparasite interactions, nest humidity, and ectoparasite community structure. Ecology 81, 958-968.

Hund, A. K., Blair, J. T. and Hund, F. W. (2015). A review of available methods and description of a new method for eliminating ectoparasites from bird nests. J. F. Ornithol. 86, 191-204.

Immediato, D., Figueredo, L. A., Iatta, R., Camarda, A., de Luna, R. L. N., Giangaspero, A., Brandão-Filho, S. P., Otranto, D. and Cafarchia, C. (2016). Essential oils and Beauveria bassiana against Dermanyssus gallinae (Acari: Dermanyssidae): Towards new natural acaricides. Vet. Parasitol. 229, 159-165.

Johnson, L. S. and Albrecht, D. J. (1993). Effects of haematophagous ectoparasites on nestling House wrens, Troglodytes aedon: who pays the cost of parasitism? Oikos 66, 255-262.

Juráni, M., Výboh, P., Zeman, M., Lamošová, D., Košt’ál, L. and Blažíček, P. (2004). Posthatching dynamics of plasma biochemistry in free-living European starlings (Sturnus vulgaris). Comp. Biochem. Physiol. - A Mol. Integr. Physiol. 138, 89-95.

Kim, S. Il, Yi, J. H., Tak, J. H. and Ahn, Y. J. (2004). Acaricidal activity of plant essential oils against Dermanyssus gallinae (Acari: Dermanyssidae). Vet. Parasitol. 120, 297-304.

King, M. O., Owen, J. P. and Schwabl, H. (2011). Injecting the mite into ecological immunology: measuring the antibody response of house sparrows (Passer domesticus) challenged with hematophagous mites. Auk 128, 340-345.

Kitaysky, A. S., Wingfield, J. C. and Piatt, J. F. (2001). Corticosterone facilitates begging and affects resource allocation in the black-legged kittiwake. Behav. Ecol. 12, 619-625. 
Lambrechts, M. M., Stenning, M. J., Adriaensen, F., Ardia, D. R., Artemyev, A. V., Atiénzar, F., Bańbura, J., Barba, E., Bouvier, J.-C., Camprodon, J., et al. (2010). The design of artificial nestboxes for the study of secondary hole-nesting birds: A review of methodological inconsistencies and potential biases. Acta Ornithol. 45, 1-26.

Lesna, I., Wolfs, P., Faraji, F., Roy, L., Komdeur, J. and Sabelis, M. W. (2009). Candidate predators for biological control of the poultry red mite Dermanyssus gallinae. Exp. Appl. Acarol. 48, 63-80.

Lindström, K. M., Foufopoulos, J., Pärn, H. and Wikelski, M. (2004). Immunological investments reflect parasite abundance in island populations of Darwin's finches. Proc. Biol. Sci. 271, 1513-9.

López-Arrabé, J., Cantarero, A., Pérez-Rodríguez, L., Palma, A. and Moreno, J. (2014). Experimental pyrethroid treatment underestimates the effects of ectoparasites in cavitynesting birds due to toxicity. Ibis (Lond. 1859). 156, 606-614.

MacDonald, I. F., Kempster, B., Zanette, L. and MacDougall-Shackleton, S. A. (2006).

Early nutritional stress impairs development of a song-control brain region in both male and female juvenile song sparrows (Melospiza melodia) at the onset of song learning. Proc. Biol. Sci. 273, 2559-2564.

Maxwell, M. (1993). Avian blood leucocyte responses to stress. Worlds. Poult. Sci. J. 49, 34-43.

Mazgajski, T. D. (2007). Effect of old nest material on nest site selection and breeding parameters in secondary hole nesters - a review. Acta Ornithol. 42, 1-14.

Merino, S. and Potti, J. (1995). Mites and blowflies decrease growth and survival in nestling pied flycatchers. Oikos 73, 95-103. 
Merino, S., Møller, A. and De Lope, F. (2000). Seasonal changes in cell-mediated immunocompetence and mass gain in nestling barn swallows: a parasite-mediated effect? Oikos 90, 327-332.

Minias, P. (2015). The use of haemoglobin concentrations to assess physiological condition in birds: a review. Conserv. Physiol. 3, 1-15.

Møller, A. (1990). Effects of parasitism by a haematophagous mite on reproduction in the barn swallow. Ecology 71, 2345-2357.

Møller, A. P. (2002). Temporal change in mite abundance and its effect on barn swallow reproduction and sexual selection. J. Evol. Biol. 15, 495-504.

Moreno, J., Merino, S., Sanz, J., Arriero, E., Morales, J. and Tomas, G. (2005). Nestling mediated immune response, body mass and hatching data as predictors of local recruitment in the pied flycatcher, Ficedula hypoleuca. J. Avian Biol. 36, 251-260.

Moret, Y. and Schmid-Hempel, P. (2000). Survival for immunity: The price of immune system activation for bumblebee workers. Science 290, 1166-1168.

Morrison, K. W., Hipfner, J. M., Gjerdrum, C. and Green, D. J. (2009). Wing length and mass at fledging predict local juvenile survival and age at first return in tufted puffins. Condor 111, 433-441.

Naguib, M., Riebel, K., Marzal, A. and Gil, D. (2004). Nestling immunocompetence and testosterone covary with brood size in a songbird. Proc. Biol. Sci. 271, 833-8.

Naguib, M., Nemitz, A. and Gil, D. (2006). Maternal developmental stress reduces reproductive success of female offspring in zebra finches. Proc. R. Soc. London B Biol. Sci. 273, 19011905. 
Nowicki, S., Peters, S. and Podos, J. (1998). Song learning, early nutrition and sexual selection in songbirds. Am. Zool. 38, 179-190.

Owen, J. C. (2011). Collecting, processing, and storing avian blood: A review. J. F. Ornithol. 82, 339-354.

Owen, J. P., Mullens, B. A., Justus, K. A. and Carde, R. T. (2005). Northern fowl mite orientation in a thermal gradient and evidence for idiothetic course control. Physiol. Entomol. 30, 293-302.

Owen, J. P., Delany, M. E., Cardona, C. J., Bickford, A. A. and Mullens, B. A. (2009). Host inflammatory response governs fitness in an avian ectoparasite, the northern fowl mite (Ornithonyssus sylviarum). Int. J. Parasitol. 39, 789-799.

Petit, C., Hossaert-McKey, M., Perret, P., Blondel, J. and Lambrechts, M. M. (2002). Blue tits use selected plants and olfaction to maintain an aromatic environment for nestlings. Ecol. Lett. 5, 585-589.

Pirrello, S., Pilastro, A. and Serra, L. (2015). Nest-dwelling ectoparasites influence the start and duration of the first pre-basic moult in the European starling Sturnus vulgaris. J. Avian Biol. 46, 001-007.

Proctor, H. and Owens, I. (2000). Mites and birds: Diversity, parasitism and coevolution. Trends Ecol. Evol. 15, 358-364.

Pryor, L. J. and Casto, J. M. Ectoparasite-induced trade-offs in somatic and physiological development. J. Exp. Zool. 201X,.

Pryor, L. J. and Casto, J. M. (2015). Blood-feeding ectoparasites as developmental stressors: Does corticosterone mediate effects of mite infestation on nestling growth, immunity, and energy availability? J. Exp. Zool. 323A, 466-477. 
Remage-Healey, L. and Romero, L. M. (2002). Corticosterone and insulin interact to regulate plasma glucose but not lipid concentrations in molting starlings. Gen. Comp. Endocrinol. 129, 88-94.

Rendell, W. B. and Verbeek, N. A. M. (1996). Are avian ectoparasites more numerous in nest boxes with old nest material? Can. J. Zool. 74, 1819-1825.

Saino, N., Calza, S., Møller, A. P. and Moller, A. P. (1998). Effects of a dipteran ectoparasite on immune response and growth trade-offs in barn swallow, Hirundo rustica, nestlings. Oikos 81, 217.

Samani, A. D., Ghahfarokhi, S. M. and Samani, A. D. (2014). An invivo survey on effect of essential oil of Achillea millefolium on wound healing in chicken (geometrical study). J. Nat. Remedies 14, 93-97.

Shutler, D. and Campbell, A. A. (2007). Experimental addition of greenery reduces flea loads in nests of a non-greenery using species, the tree swallow Tachycineta bicolor. J. Avian Biol. 38, 7-12.

Sikes, R. K. and Chamberlain, R. W. (1954). Laboratory observations on three species of bird mites. J. Parasitol. 40, 691-697.

Smith, K. D. and Barber, C. A. (2012). Hematocrit does not indicate condition in nestling or adult European starlings. Wilson J. Ornithol. 124, 788-792.

Strasser, E. H. and Heath, J. A. (2013). Reproductive failure of a human-tolerant species, the American kestrel, is associated with stress and human disturbance. J. Appl. Ecol. 50, 912919. 
Tauk, B. S., Drobatz, K. J., Wallace, K. A. and Hess, R. S. (2015). Correlation between glucose concentrations in serum, plasma, and whole blood measured by a point-of-care glucometer and serum glucose concentration measured by an automated biochemical analyzer for canine and feline blood samples. J. Am. Vet. Med. Assoc. 246, 1327-1333.

Tomás, G., Merino, S., Moreno, J. and Morales, J. (2007). Consequences of nest reuse for parasite burden and female health and condition in blue tits, Cyanistes caeruleus. Anim. Behav. 73, 805-814.

Tripet, F. and Richner, H. (1997). Host responses to ectoparasites: Food compensation by parent blue tits. Oikos 78, 557-561.

Tschirren, B., Richner, H. and Schwabl, H. (2004). Ectoparasite-modulated deposition of maternal androgens in great tit eggs. Proc. R. Soc. B Biol. Sci. 271, 1371-5.

Veiga, J. A. S., Roselino, E. S. and Migliorini, R. H. (1978). Fasting, adrenalectomy, and gluconeogenesis in chicken and a carnivorous bird. Am. J. Physiol. Integr. Comp. Physiol. 234, R115-R121.

Williams, T. D., Fronstin, R. B., Otomo, A. and Wagner, E. (2012). Validation of the use of phenylhydrazine hydrochloride (PHZ) for experimental manipulation of haematocrit and plasma haemoglobin in birds. Ibis (Lond. 1859). 154, 21-29.

Wimberger, P. H. (1984). The use of green plant material in bird nests to avoid ectoparasites. Auk 101, 615-618.

Wingfield, J. C., Smith, J. P. and Farner, D. S. (1982). Endocrine responses of white-crowned environmental stress sparrows to environmental stress. Condor 84, 399-409. 


\section{FIGURES}

A

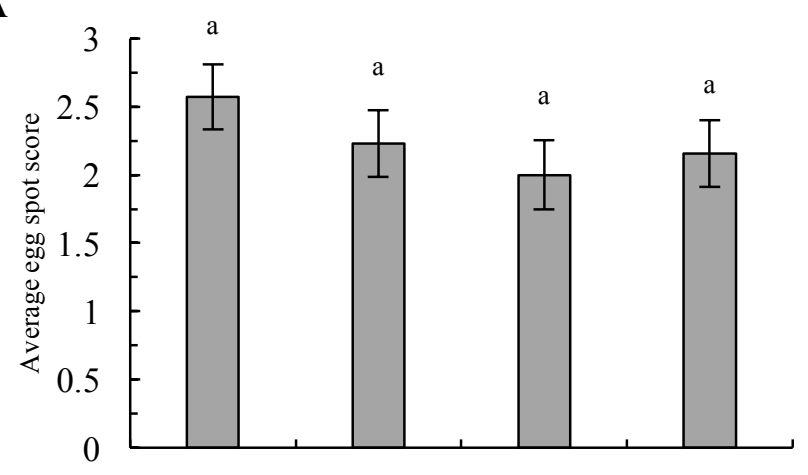

B
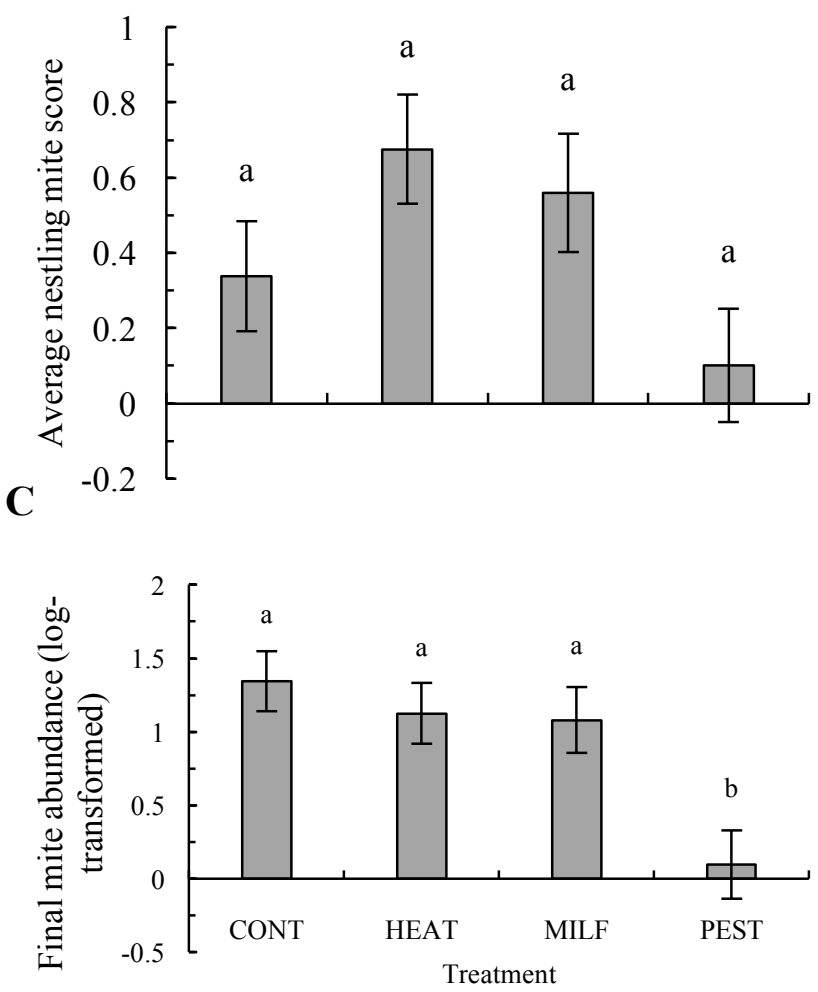

Figure 1. Mite abundance analyses. (A) Average egg spottiness scores prior to treatments ( \pm SEM; N=53). (B) Average BD10 nestling mite score ( \pm SEM; N=53). (C) Post-fledging mite abundance ( \pm SEM; $N=53$ ). Different superscript letters indicate differences amongst treatments $(\mathrm{p}<0.05)$. Least square means used. 


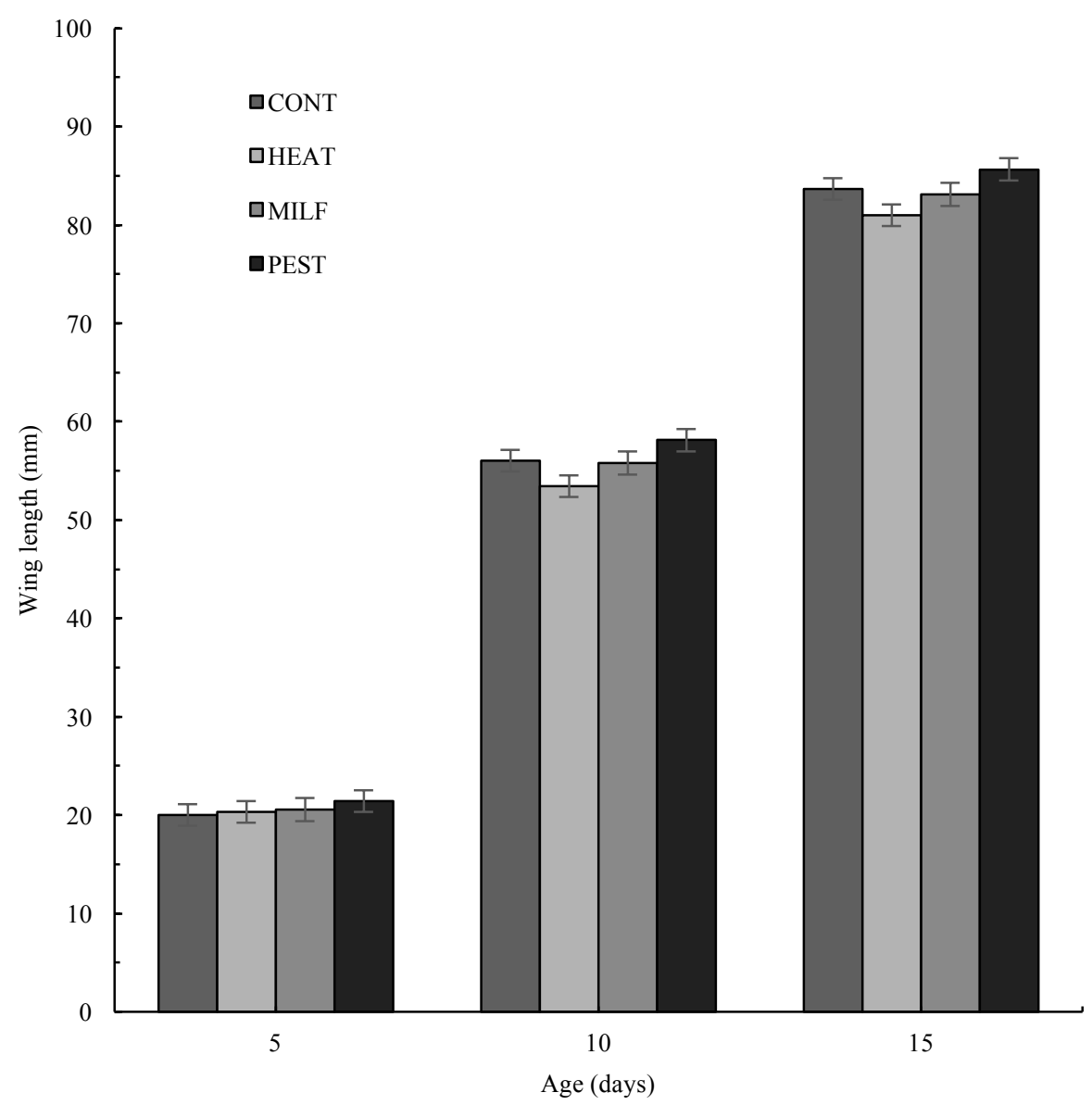

Figure 2. Wing length across treatments for BD 5, 10 and 15 nestlings. Least square means (mm $\pm \mathrm{SE}$; N=53).used. 


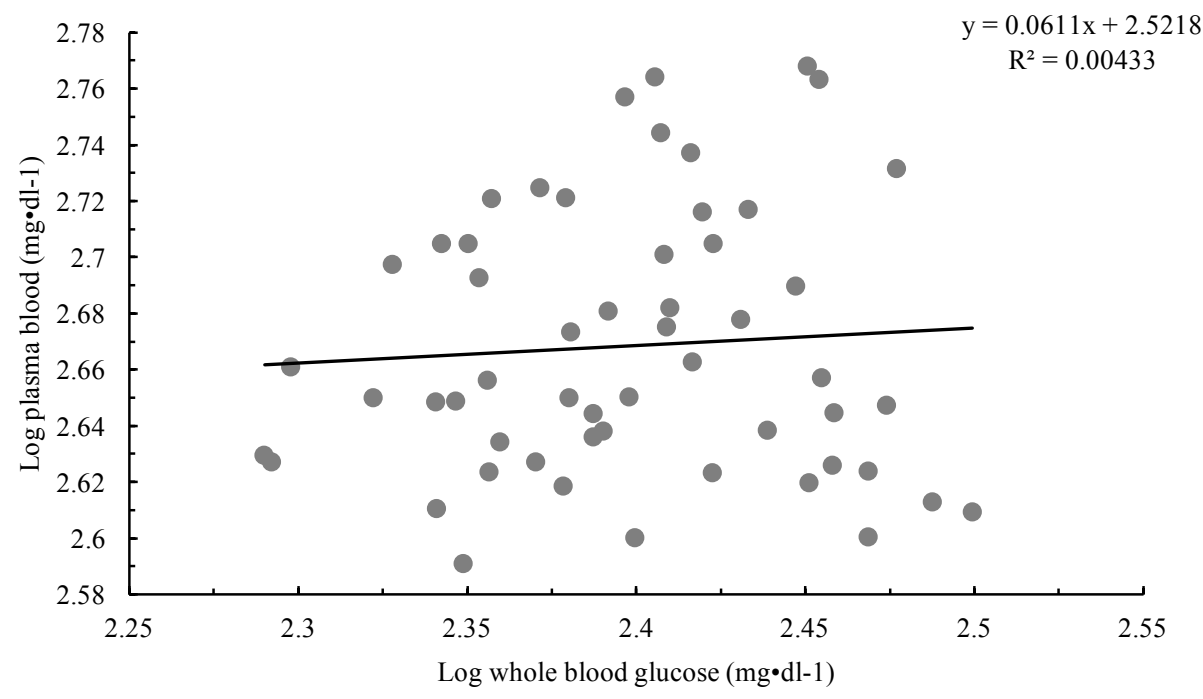

Figure 3. Correlation of whole blood and plasma glucose concentrations. Least square means (Mean mg•dl ${ }^{-1} ; \mathrm{N}=53$ ) used. Both parameters are $\log _{10}$ transformed. 


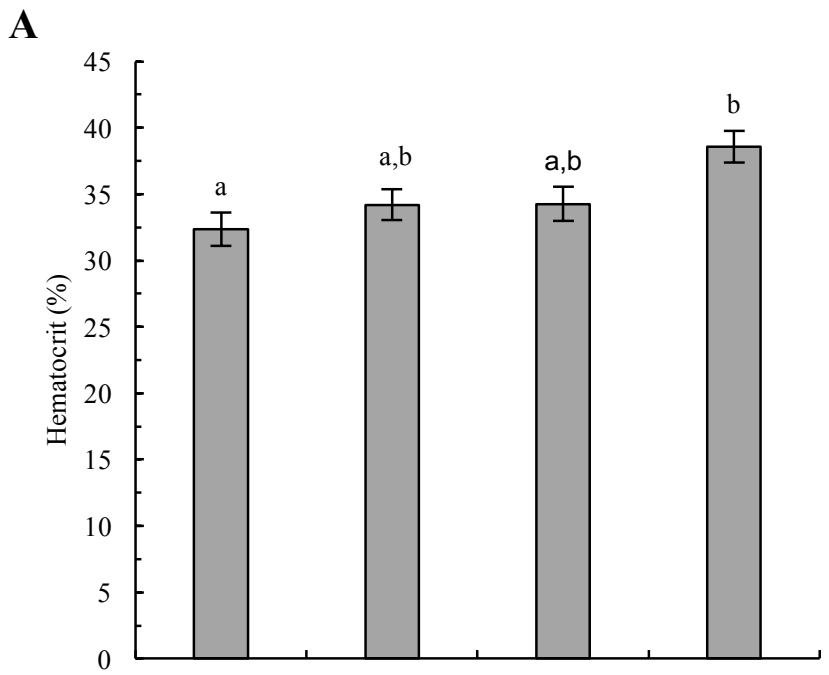

\section{B}

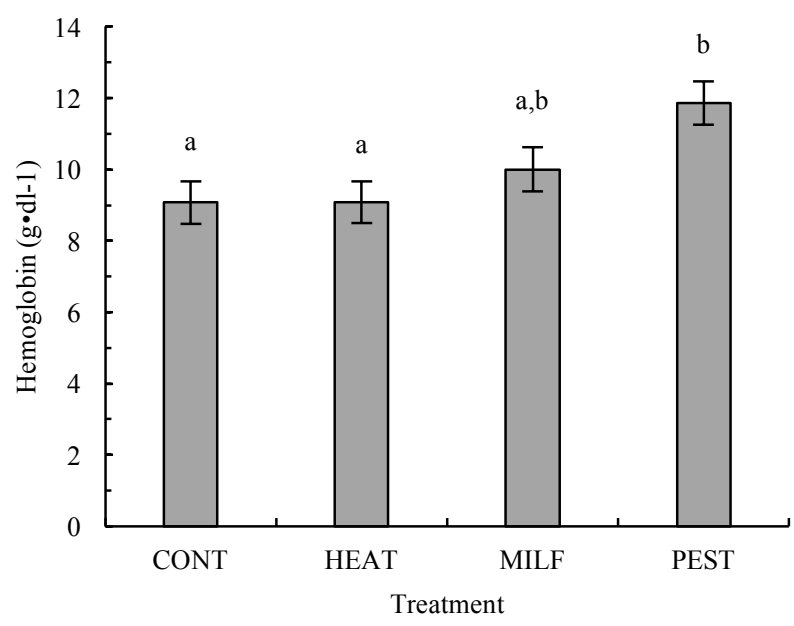

Figure 4. Blood parameter measurements on brood day 15 nestlings across treatment groups.

(A) Mean hematocrit volume $( \pm \mathrm{SEM})$; (B) Average hemoglobin concentration $\left(\mathrm{g} \bullet \mathrm{dl}^{-1} \pm \mathrm{SE}\right)$.

Different superscript letters indicate differences between treatments $(p<0.05)$. 